\title{
$\beta$-diversity as a measure of species turnover along the salinity gradient in the Baltic Sea, and its consistency with the Venice System
}

\author{
S. Bleich ${ }^{1, *}$, M. Powilleit ${ }^{1}$, T. Seifert ${ }^{2}$, G. Graf ${ }^{1}$ \\ ${ }^{1}$ Institute of Biological Sciences-Marine Biology, University of Rostock, Albert Einstein Strasse 3, 18059 Rostock, Germany \\ ${ }^{2}$ Leibniz Institute for Baltic Sea Research, Warnemünde, Seestrasse 15, 18119 Rostock, Germany
}

\begin{abstract}
Transition zones between marine and freshwater environments are characterized by a pronounced salinity gradient and concomitant variation in invertebrate species richness. Here we use the $\beta$-diversity concept to depict the species turnover of macrobenthic species along the salinity gradient of the Baltic Sea with salinities ranging from 34 in the transition zone to the North Sea to less than 5 in the Bothnian Sea. Based on 250 data sets from 72 locations that were grouped into 2 habitats defined according to their depths and sediment types (shallower: 15 to $19 \mathrm{~m}$, fine to medium sand; deeper: 20 to $35 \mathrm{~m}$, silt to silty sand), we calculated the Jaccard dissimilarity index ( $\left.\beta_{1-J}\right)$ as a measure of species turnover. To keep the focus on the salinity gradient, sediment characteristics and the time period covered by the data sets (spring and summer 1995 to 2005) were predefined. The mean hydrographic parameters, including temperatures, salinities and dissolved oxygen (DO) concentrations of the sample locations were derived from model calculations based on data gathered over a 3 yr period before sampling. At the deeper stations, the total number of macrofaunal species was 255 , while at the shallower ones, 172 taxa were found. Statistical analyses revealed salinity to be the main structuring factor for macrobenthic species turnover. High correlations between the $\beta_{1-J}$ index and mean salinities in both habitats (Spearman's rank correlation coefficient $\rho=0.88$ in shallower and $\rho=0.86$ in deeper areas) confirmed these findings. $\beta$-diversity values with median $\beta_{1-J}$ varied between 51 and $65 \%$ within the salinity classes eu-, poly-, $\alpha$-meso- and $\beta$-mesohaline, while values of 75 to $100 \%$ characterized between-group comparisons. Furthermore, these high $\beta$-diversity values depict a discontinuous change in the communities and are found at salinities of around 10,18, and 30, which ties in fairly well with the existing salinity boundaries postulated by the Venice System.
\end{abstract}

KEY WORDS: Species turnover $\cdot \beta$-diversity · Salinity gradient $\cdot$ Macrofauna $\cdot$ Venice System • Baltic Sea

\section{INTRODUCTION}

The change in the community structure along the salinity gradient in the Baltic Sea was described by Remane (1934). Starting at the fully marine end of his famous graph, a continuous decrease in species richness can be seen. At salinities between approximately 5 and 8 a species minimum was identified, while numbers increased again towards the freshwater end of the gradient.
For terrestrial ecosystems Gleason (1926) proposed that the relationships between coexisting species in a community are simply the result of similarities in the species' requirements and tolerances. Taking this concept as being widely accepted in modern ecology, associations of species would be difficult to predict and community boundaries need not be sharp.

The debate on boundaries in brackish water systems leads to various suggestions that are quite different (see Hiltermann 1963). In 1958, scientists 
agreed on the Venice System (Caspers 1959), in which the following generalized salinity class boundaries were defined: euhaline zone $>34$ to 30 , polyhaline zone 30 to $18, \alpha$-mesohaline zone 18 to 10 , $\beta$-mesohaline zone 10 to $5, \alpha$-oligohaline zone 5 to 3 , $\beta$-oligohaline zone 3 to 0.5 , and limnetic zone 0.5 to 0 . The System is widely used, e.g. in the implementation of the European Union's (EU) Water Framework Directive in the coastal waters of the Baltic Sea (von Weber 2004). The Venice System's boundaries are also consistent with distribution limits determined by coenosis (Hiltermann 1963). Nevertheless, other studies have claimed that no objective criteria exist for these boundaries (e.g. Bulger et al. 1993). Except for the minimum species richness at salinities from $\sim 5$ to 8 , the boundaries of the Venice System cannot be derived from Remanes' species-salinity curve (Remane 1934), which only illustrates a continuous loss of species from the marine sector down to the level at salinities $\sim 5$ to 8 . However, this Artenminimum can only be applied to benthic organisms, as shown by Telesh et al. (2011). These authors instead found a high biodiversity or even a maximum in pelagic protists and planktonic organisms in this salinity range.

Whittaker (1960) subdivided the diversity of species into $\alpha-, \beta$-, and $\gamma$-diversity. $\alpha$-diversity is the diversity of a particular spatial unit, e.g. a single station. It is described by species number or by diversity indices such as the Shannon-Wiener index $\left(H^{\prime}\right)$ or the Simpson-Yule index $(1 / D)$. $\gamma$-diversity describes the diversity of large entities such as landscapes.

$\beta$-diversity is a measure of the change in species composition. The extent of species replacement or biotic change along environmental gradients is defined as 'species turnover', or the change in species composition from one community to another (Whittaker 1972), or as variation in species composition among sites in a geographic area (Legendre et al. 2005). More than 20 different kinds of $\beta$-diversity indices were summarized by Koleff et al. (2003) and Tuomisto (2010). However, the strength of most indices with regard to species turnover is controversially discussed (Vellend 2001).

There are 2 basic ways of using the $\beta$-diversity concept: (1) $\beta$-diversity is a measure of species turnover in an area, and of the diversity or heterogeneity of that area (e.g. Wilson \& Shmida 1984, Novotny \& Weiblen 2005), recently termed 'regional diversity' (Tuomisto \& Ruokolainen 2008), and (2) $\beta$-diversity is a measure of species turnover along environmental gradients, also known as 'pairwise beta diversity' (Tuomisto \& Ruokolainen 2008). This latter approach has rarely been used to date in marine ecology (e.g. Ellingsen 2002, Hillebrand et al. 2010).
Although studies dealing with the general distribution of macrozoobenthos along salinity gradients do exist (e.g. Dauer et al. 1987, Nanami et al. 2005, Zettler et al. 2007), only few use the $\beta$-diversity-concept in this context (e.g. Piscart et al. 2005, Giberto et al. 2007, Sousa et al. 2008). The present study builds on the $\beta=$ diversity concept using dissimilarity or distinctness measures also known as complementarities (e.g. Colwell \& Coddington 1994, Ellingsen \& Gray 2002) and looks at the species turnover between data sets along the gradient of average salinity in the Baltic Sea. Along with sediment properties, oxygen $\left(\mathrm{O}_{2}\right)$ supply and recruitment through pelagic larvae, salinity is a main factor influencing the distribution of benthic macrofauna (e.g. Perus \& Bonsdorff 2004, Teske \& Wooldridge 2004, Udalov et al. 2004).

The aim of this study was to test the salinity class boundaries of the Venice System using the $\beta$-diversity concept. Because this classification system is exclusively based on salinity, we selected only stations with minimum differences in other structuring factors, such as $\mathrm{O}_{2}$ content and sediment type. This selection was done by pre-selecting available data sets with predefined habitat types within narrow environmental ranges.

\section{MATERIALS AND METHODS}

Study area and macrozoobenthos data sources. The study area covered the Skagerrak, the Kattegat, the Belts and Sound, the western Baltic Sea and the Baltic Proper and extended to the Bothnian Sea. The salinity in the bottom water ranged from 30 to 34 in the Skagerrak and Kattegat to 4 to 5 in the Bothnian Sea. The transition region (the Belts, the Sound and the western Baltic Sea) was characterized by strong salinity variations and an average salinity of 10 to 25 . The species turnover of the macrofauna was investigated in 2 different habitats: those locations with depths between 15 and $19 \mathrm{~m}$ that had a fine to medium sandy bottom (shallower habitat) and those with depths between 20 to $35 \mathrm{~m}$ that had a silt to silty sand bottom (deeper habitat) (Table 1). Sediment classification was based on sediment grain size and, if data were available, loss on ignition.

Table 1. Physical characteristics of the 2 habitats. Both habitats were sampled in spring to early summer of the years 1995 to 2005 , and had an $\mathrm{O}_{2}$ concentration $>2 \mathrm{ml} \mathrm{l}^{-1}$

\begin{tabular}{|lccc|}
\hline & $\begin{array}{c}\text { Depth } \\
(\mathrm{m})\end{array}$ & Sediment & $\begin{array}{c}\text { Ignition loss } \\
(\% \text { dry wt })\end{array}$ \\
\hline $\begin{array}{l}\text { Shallower } \\
\text { Deeper }\end{array}$ & $\begin{array}{c}15-19 \\
20-35\end{array}$ & $\begin{array}{c}\text { Fine to medium sand } \\
\text { Silty sand to silt }\end{array}$ & $\begin{array}{c}0.2-1 \\
>3\end{array}$ \\
\hline
\end{tabular}


Table 2. Sampling parameters and information about the 12 sources used to obtain data sets for this study. BioMad: Database on Marine Biological Monitoring Data; SMHI: Swedish Meteorological-Hydrological Institute; BKVF: Blekingekustens Vattenvårdsförbund; KMRS: Kristineberg Marine Research Station; NLST: Länsstyrelsen i Hallands län; SMRC: Stockholm University Marine Research Center; UMSC: Umeå University; BSH: Bundesamt für Seeschifffahrt und Hydrographie; LANU: Landesamt für Natur und Umwelt Schleswig-Holstein; LUNG: Landesamt für Umwelt, Naturschutz und Geologie; NMFRI: National Marine Fisheries Research Instiute; CORPI: Coastal Research and Planning Institute, Klaipeda University; IMWM: Institute of Meteorology and Water Management; IFAOE: Institut für Angewandte Ökologie; UR: University of Rostock. n: no. of data sets, N: no. of stations

\begin{tabular}{|c|c|c|c|c|c|c|c|c|c|c|}
\hline \multirow{3}{*}{$\begin{array}{l}\text { Region } \\
\text { Baltic Proper }\end{array}$} & \multicolumn{2}{|c|}{$\begin{array}{l}\text { Shallower } \\
\text { habitats }\end{array}$} & \multicolumn{2}{|c|}{$\begin{array}{l}\text { Deeper } \\
\text { habitats }\end{array}$} & \multirow[t]{2}{*}{$\begin{array}{c}\text { Grab sampling } \\
\text { device }\end{array}$} & \multirow[t]{2}{*}{$\begin{array}{l}\text { Sampling } \\
\text { area }\left(\mathrm{cm}^{2}\right)\end{array}$} & \multirow[t]{2}{*}{$\begin{array}{l}\text { No. of } 1 \\
\text { replicates }\end{array}$} & \multirow[t]{2}{*}{$\begin{array}{l}\text { Mesh size } \\
\mathrm{s} \quad(\mathrm{mm})\end{array}$} & \multirow[t]{2}{*}{ Source } & \multirow[t]{2}{*}{$\begin{array}{l}\text { Organization, } \\
\text { country }\end{array}$} \\
\hline & & & & & & & & & & \\
\hline & 9 & 4 & - & - & van Veen & 1202 & 3 & 1 & BioMad/SMHI & BKVF, Sweden \\
\hline $\begin{array}{l}\text { Skagerrak/ } \\
\text { Kattegat }\end{array}$ & - & - & 46 & 9 & Smith McIntyre & 1000 & 4 & 1 & BioMad/SMHI & KMRS, Sweden \\
\hline Kattegat & 3 & 1 & 7 & 3 & Smith McIntyre & 1000 & 5 & 1 & BioMad/SMHI & NLST, Sweden \\
\hline Baltic Proper & - & - & 8 & 1 & van Veen & $1000-1045$ & $1-3$ & 1 & BioMad/SMHI & SMRC, Sweden \\
\hline $\begin{array}{l}\text { Baltic Proper/ } \\
\text { Bothnian Sea }\end{array}$ & 26 & 3 & 91 & 13 & van Veen & $977-1125$ & 1 & 1 & BioMad/SMHI & UMSC, Sweden \\
\hline Belt Sea & 16 & 3 & 4 & 3 & van Veen & 1000 & 3 & 1 & $\begin{array}{l}\text { S. Wilhelms, } \\
\text { BSH data }\end{array}$ & $\begin{array}{l}\text { LANU and LUNG, } \\
\text { Germany }\end{array}$ \\
\hline Baltic Proper & 2 & 1 & - & - & van Veen & 1000 & 1 & 0.5 & V. Didžiulis & CORPI, Lithuania \\
\hline $\begin{array}{l}\text { Belt Sea/ } \\
\text { Baltic Proper }\end{array}$ & 19 & 18 & 1 & 1 & van Veen & $1000-1072$ & $1-3$ & 1 & H. Sordyl & IFAOE, Germany \\
\hline $\begin{array}{l}\text { Belt Sea/ } \\
\text { Baltic Proper }\end{array}$ & 3 & 3 & 1 & 1 & van Veen & 1000 & 3 & 1 & M. von Weber & LUNG, Germany \\
\hline Baltic Proper & 5 & 1 & - & - & van Veen & 1000 & 3 & 1 & E. Łusiak-Pastuszak & IMWM, Poland \\
\hline Baltic Proper & 7 & 7 & - & - & van Veen & 1000 & 3 & 1 & J. Warzocha & NMFRI, Poland \\
\hline Belt Sea & 2 & 2 & - & - & van Veen & 1000 & 5 & 1 & Proprietary data & UR, Germany \\
\hline
\end{tabular}

As we focused on the salinity gradient, we excluded stations with hypoxic conditions $\left(<2 \mathrm{ml} \mathrm{O}_{2} \mathrm{l}^{-1}\right)$, as these lead to an impoverishment of benthic invertebrates. Therefore, we restricted the sampling period to spring and early summer to avoid events of temporary $\mathrm{O}_{2}$ deficiency that occur from August to October in some regions (e.g. Josefson \& Hansen 2004). By using the 2 habitats with differing depth intervals and corresponding predefined sediment and hydrographical parameters, we were able to test the species turnover not influenced by depth and sediment type. In this study we used our own data together with data from 11 other sources on the Baltic Sea, the Skagerrak and the Kattegat (Table 2).

Only stations that fit to one of our predefined habitats were selected (Table 1). No suitable stations were found on the Swedish coast of the Baltic Proper in the shallower habitat or on the Polish coast in the deeper one. For the shallower habitat, we used 92 data sets from 42 stations and for the deeper one, 158 data sets from 30 stations (Fig. 1). A data set corresponds to a sample taken at one station at a given time. No appropriate stations were found above $64^{\circ} \mathrm{N}$ in either habitat.

Model data. Since observations were not available for water temperature, salinity and concentration of dissolved oxygen (DO) at all the sampling sites, these data have been extracted from a numerical model hindcast. The model is an adaptation of the Modular Ocean Model MOM-3 (Pacanowski \& Griffies 2000) for the whole Baltic Sea and includes an ecosystem module (Neumann \& Schernewski 2008). The model was driven by realistic forcing functions; the meteorology was taken from the Spectrally Nudged Regional Model (SN-REMO) downscaling (Feser et al. 2001), and the freshwater and nutrient discharge from rivers were compiled from Bergström \& Carlsson (1994) and Stålnacke et al. (1999). The river inputs were extrapolated on the basis of the yearly regional runoff published by the Swedish Meteorological-Hydrological Institute (SMHI) in the Helsinki Commission (HELCOM) indicator fact sheets (www.helcom.fi/BSAP assessment/ifs/en_GB/cover/). A long-term model run covering the period 1960 to 2007 was carried out with a grid resolution of $3 \mathrm{n}$ miles $(5.5 \mathrm{~km})$, providing a continuous time series of the 3-dimensional distribution of water temperature, salinity and DO concentration based on $5 \mathrm{~d}$ mean values.

The hydrographic background data used in this investigation were extracted from the model fields by selecting model cells with comparable water depths in the vicinity of the sampling sites. The real bathymetry was smoothed somewhat by the coarse model resolution, especially at the coastal margins, because one mean water depth was allocated to each approximately 


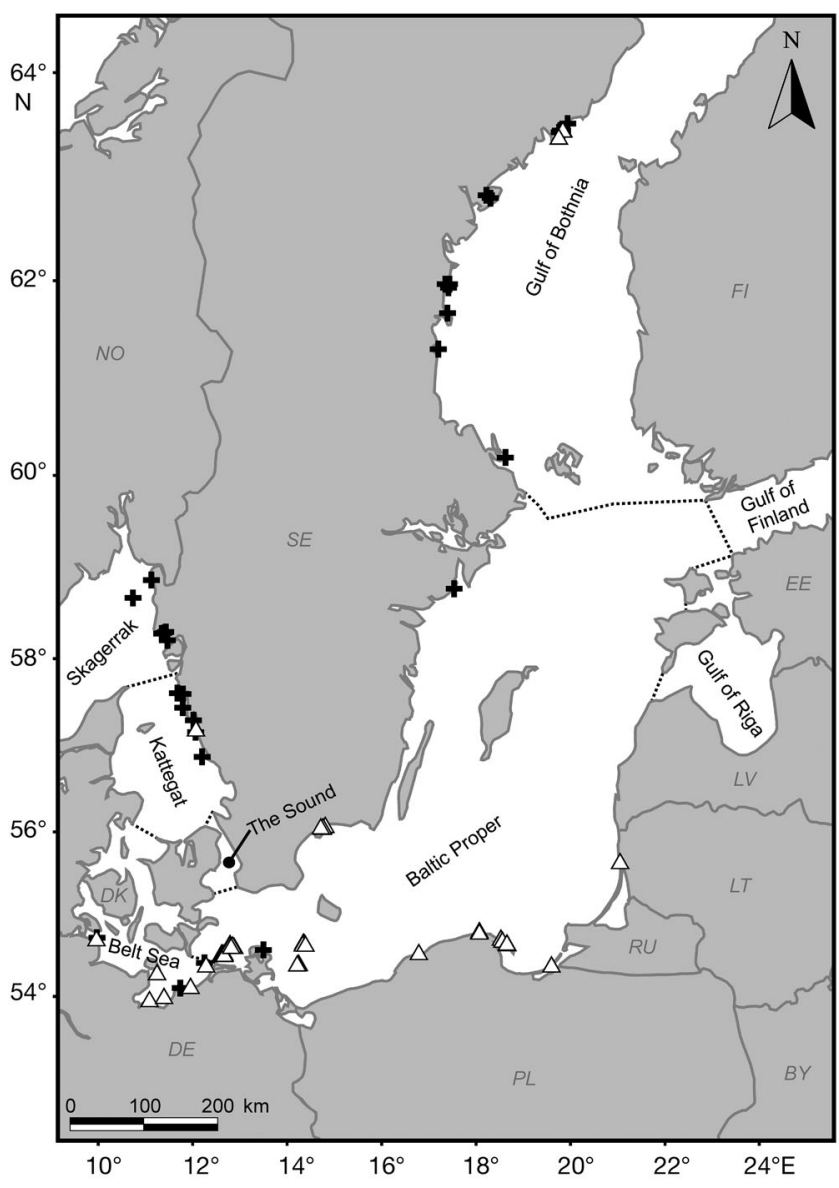

Fig. 1. Sampling stations in the Baltic Sea: $(\Delta)$ stations in shallower habitats of $15-19 \mathrm{~m}$ depth with a fine to medium sand bottom and (+) stations in deeper habitats of 20-35 m depth with a silty sand to silt bottom

$30 \mathrm{~km}^{2}$ model grid cell. In order to show how the simulated hydrography corresponds to observations, model data were compared to appropriate stations from the data set compiled by HELCOM (unpubl. data, www. ices.dk) using the monitoring measurements carried out by the countries bordering the Baltic Sea. A total of 50 HELCOM stations providing near-bottom measurements of temperature, salinity, and DO in the 15-35 m depth range within the time window of 1995 to 2005 were identified. The regional distribution of the observations resembles the distribution of the sampling sites along the southern coast of the Baltic from the southwestern Belt Sea to the Curonian Lagoon. However, the HELCOM stations in the Kattegat were located on the western coast, while those in the Bothnian Sea were located on the eastern coast. Some data were also available for the Gulf of Riga and the Gulf of Finland.

The variance and the mean values of observed bottom salinities were compared with model results. A salinity gradient from the mixo-euhaline conditions in the Kattegat to the oligohaline zone in the Bothnian Sea, i.e. the southern part of the Gulf of Bothnia (salinity <5) was reflected by both the data and the model results. The decrease in bottom salinity from 22 to 20 in the Danish Belt Sea to around 7 in the southern Baltic was also reproduced by the model. However, the mean salinity was overestimated in the simulation by values of 1.5 in the southern Baltic Sea and up to 4 at some locations in the Belt Sea. The large variance at stations with mean bottom salinity $>10$ was similar to our data, but here too, the model tended to overestimate salinities. These deviations are partly accounted for by the coarse model resolution, as point measurements at stations were compared with model cells of over $30 \mathrm{~km}^{2}$. Moreover, the comparison is biased by the different sample density of the HELCOM stations. For temperature and DO concentration, the model-data comparisons showed average uncertainties of $\pm 1^{\circ} \mathrm{C}$ and $\pm 1 \mathrm{ml} \mathrm{l}^{-1}$, with a tendency to overestimate the occurrence of $\mathrm{O}_{2}$ depletion along the coasts of the central Baltic Sea. This discrepancy was obvious in the vicinity of the rivers Odra, Daugava and Narva, where $\mathrm{O}_{2}$ consumption increases after strong algae blooms that result from riverine nutrient inputs.

Despite the deviations between the hindcast and the observations, the continuous model time series provided a convenient way of estimating the average hydrographic conditions at the investigated sites within a time span before sampling (see 'Near-bottom hydrographic parameters').

Macrozoobenthos sampling and processing. The sampling and analysis of the macrofauna was carried out according to standard methods (HELCOM 1988). All samples were collected with a van Veen or Smith McIntyre grab (Table 2), rinsed through a sieve with a mesh size of $1 \mathrm{~mm}$ (at 1 station with $0.5 \mathrm{~mm}$ ), and the residue was fixed and conserved with a $4 \%$ formalin seawater solution. Both grab types covered a sampling area of approximately $0.1 \mathrm{~m}^{2}$ and yielded similar penetration depths in sandy sediments (Eleftheriou \& Moore 2005). Only data sets with 1 to 5 replicates were included in the analysis.

The influence of the number of replicates on species number was tested by performing correlation analyses. We tested the species number against the number of replicates as well as the species number against the mean salinity. According to the strong salinity gradient, we tested the correlations for all salinity classes and for each salinity class separately.

The station at which a $0.5 \mathrm{~mm}$ mesh net was used was located in the $\beta$-mesohaline salinity range and was characterized by low overall species richness. As a result, the smaller mesh size had a negligible effect on species numbers. 
Animals were taxonomically determined, if possible, to species level. The following groups were determined to higher taxonomical levels only: Arachnida, Diptera, Nemertini, Oligochaeta, Pantopoda, Phoronida, Platyhelminthes and Trichoptera.

The lists of species at all data sets were placed on a common taxonomic level using the World Register of Marine Species database (WoRMS, www.marinespecies.org). Species names were also checked with the European Register of Marine Species database (ERMS, www.marbef.org/data/erms.php). Misspellings were corrected, and species and genus names were validated and, if necessary, corrected. Epifauna, e.g. Bryozoa, Tunicata and Parasids, were excluded. Also removed from the records were Mysidacea, Nematoda, Ostracoda and Turbellaria. Because the data sets originated from different sources during the 1995-2005 period, changes in the taxonomy of single taxa, as in the genus Marenzelleria (Bick 2005), were possible and different taxonomic levels were used in determination, some generalizations to higher taxonomical levels and further adjustments were made for the gammarid, oligochaete and insect groups. In addition, all individuals of the supra-specific taxa Aricidea sp., Cylichnia sp., Edwardsia sp., Hydrobia sp., Marenzelleria sp. and Ophiura sp. were reduced to the genus. In most cases, grouping according to genus did not affect the results because of the high number of species at the stations in question. In areas with a very low number of species already (at low salinities), such grouping may lead to a slight underestimate of species richness and to an approximation of community composition. Nevertheless, such generalizations were necessary in order to generate a consistent data compilation.

Statistical analyses. $\boldsymbol{\alpha}$-diversity: Both species richness $(S)$ and the Shannon-Wiener index of diversity $\left(H^{\prime}\right.$ $\log _{2}$ ) (Shannon \& Weaver 1949) were used to describe $\alpha$-diversity. $H^{\prime}$ was calculated on the basis of the corrected species abundance lists. Diversity indices were calculated using the PC program 'PRIMER 6 for Windows' (Clarke \& Gorley 2006).

$\boldsymbol{\beta}$-diversity: To assess $\beta$-diversity, the indices in Eqs. (1) \& (2) were used. Clarke et al. (2006) proposed the Bray-Curtis dissimilarity index $\left(D_{12}^{B-C}\right)$ that estimates diversity on the basis of the number of individuals $X$ of species $i$ in 2 samples [1,2],

$$
D_{12}^{B-C}=100 \times\left(\frac{\sum_{i=1}^{n}\left|X_{i 1}-X_{i 2}\right|}{\sum_{i=1}^{n}\left(X_{i 1}+X_{i 2}\right)}\right)
$$

where $n$ is usually the total number of species. If the number of individuals is reduced to presence-absence, $X_{i 1}$ and $X_{i 2}$ take on the value 0 or 1 . We used presence-absence data for $D_{12}^{B-C}$ and renamed this index to $\beta_{B C}$, which is equal to Whittaker's index ( $\beta_{W}$; Whittaker 1972) if presence-absence data are used, as is the case in this study. For this reason, no separate calculation of $\beta_{W}$ was carried out. Alternatively, diversity can be evaluated from the number of species found at the sampling locations. If $a$ is the number of common species in the samples being compared, and $b$ and $C$ denote the numbers of species which occur only at Sample 1 or Sample 2, the $\beta$-diversity index according to Magurran (2004) reads as follows,

$$
\beta_{1-J}=100 \times\left(1-\frac{a}{a+b+c}\right)
$$

Eq. (2) is also known as the Jaccard dissimilarity, Jaccard distance, Jaccard complementarity or Jaccard distinctness index (e.g. Stohlgren et al. 1997, Boyce \& Ellison 2001, Chao et al. 2005, Denœud \& Guénoche 2006).This index is widely used to analyze species turnover (e.g. Chytrý et al. 2001; Anderson et al. 2006; Terlizzi et al. 2009) and is one of the best-performing (dis)similarity indices (Boyce \& Ellison 2001). Rearranging the terms in Eqs. (1) \& (2),

$$
\begin{aligned}
& \beta_{B C}=100 \times \frac{(b+c)}{(2 a+b+c)} \\
& \beta_{1-J}=100 \times \frac{(b+c)}{(a+b+c)}
\end{aligned}
$$

shows that $\beta_{B C}$ and $\beta_{1-J}$ are very similar, although $\beta_{1-J}$ always yields higher values.

A presence-absence matrix, also known as a species occurrence matrix (e.g. Ferreira \& Petrere 2009), was created from the corrected species abundance lists along the gradients within each of the depth ranges (shallower and deeper).

On the basis of the presence-absence data, $\beta$ diversities were calculated using the programs EstimateS (Colwell 2005) and 'PRIMER 6 for Windows' (Clarke \& Gorley 2006). For both indices, the factor 100 was introduced, corresponding to values of 0 to $100 \%$ species turnover. On the basis of the $\beta$-diversities calculated for each pairwise comparison of data sets, a dissimilarity matrix was created. Using this matrix, an ordination was conducted by means of non-metric multidimensional scaling (nMDS) with PRIMER 6. The data sets were assigned according to their average salinity to classes of the Venice System. One data set from the shallower depth range that had an average 3-yr salinity of 29.3 was at the most saline end of the polyhaline zone. The other 2 data sets from this station had average salinities, which placed them in the euhaline zone. Accordingly, this station was treated as being in the euhaline zone.

On the basis of their species presence-absence the significance of the assignment of the data sets to the 
classes derived from the Venice System were tested using the ANOSIM module of PRIMER 6.

Additional tests: The sample-size sample-effort dependence was tested for by calculating Pearson's correlation coefficients between species richness and the number of replicates per data set, as well as between species richness and salinity. Differences between $\beta$-diversities $\left(\beta_{1-J}\right)$ within each of the salinity classes of the Venice System and those between these classes were tested by performing a Mann-Whitney test. The same test followed by a Bonferroni correction was used for all pair-wise comparisons between salinity classes and performed in SPSS version 15 .

The SIMPER (similarity percentage) analysis (Clarke 1993) of PRIMER 6 was used to determine the contributions to the average Bray-Curtis dissimilarity between pairs of groups of data sets (i.e. all sites of Salinity Class 1 against all sites of Class 2). SIMPER also determined the average similarity within and between each group. In analogy to the $\beta_{1-J}$ index (see Eq. 4), this resulted in mean $\beta$-diversities $\left(\beta_{B C}\right)$ within and between salinity classes.

A nonparametric Mantel-type test using Spearman correlation coefficients between the 2 dissimilarity matrices (RELATE procedure in PRIMER 6) was used to determine if there was a relationship between the change of species composition ( $\beta$-diversity) and the following abiotic parameters: salinity, DO concentration, and temperature determined from the model and distance between the stations. The RELATE procedure is a test of the hypothesis that no relation exists between the environmental and biological data. We have used the multiple data set version of RELATE named 2STAGE. For this purpose the distance between stations was calculated on the basis of their geographical positions using the program 'Geographic Distance Matrix Generator' (Ersts 2009). Where the direct route between stations was shorter than the real water distance, values were adjusted accordingly using the newly introduced auxiliary points referred to as junctions. For calculations of distances between stations in the Skagerrak/Kattegat and all other stations in the Baltic, the Great Belt and the Langeland Belt were treated as 'gateways' to the Baltic Sea because $73 \%$ of the water exchange between the Baltic and the North Sea/North Atlantic occurs through these gateways (e.g. HELCOM 1986, Josefson \& Hansen 2004).

With 2STAGE we checked which variables were strongly correlated with mean salinity. We removed those variables before trying another correlation test, BIOENV, in PRIMER 6. BIOENV selects the environmental variables that explain community patterns the best by maximizing a rank correlation between their respective resemblance matrices.

\section{RESULTS}

\section{Near-bottom hydrographic parameters}

The continuous time series extracted from the model hindcast (see 'Model data') were used to reconstruct the hydrographic conditions at the stations within a time window of $3 \mathrm{yr}$ before the data sets were taken. The variance of salinity, water temperature and DO concentration above sea bottom is displayed in Fig. 2. Data sets were ranked by the mean salinity measured at the station and then numbered in order of decreasing salinity $(1=$ highest mean salinity, 92 and $158=$ lowest mean salinity at shallower and deeper stations, respectively) so that the resulting distribution reflects the regional salinity gradient as well as the temporal changes at repeatedly sampled sites. The regional differences in available observations should be noted when interpreting this figure.

The salinity gradient (mean salinity), which ranged from 34 in the Skagerrak to 5 in the Bothnian Sea, was covered in both habitats. The deeper stations (20 to $35 \mathrm{~m}$ ) in Skagerrak and Kattegat provided 53 data sets corresponding to euhaline conditions with salinity $>30$, while the transition zone with salinities of 25 to 10 was well represented by the shallower stations (15 to $19 \mathrm{~m}$ ) in the Belt Sea (Data Sets 4 to 34). In contrast, there were only 3 data sets from one shallow station in the Kattegat, and the few deeper stations in the transition zone (around Data Sets 54 to 59) are misleading in suggesting a sharp salinity gradient in this habitat (Fig. 2A,B). Both habitats showed significant temporal variation in salinities above 10, such as in the Skagerrak, Kattegat and the Belt Sea. Within the Baltic Sea, salinity variation was very low, shown by the sharp decrease of ranges at salinities $<10$ (Fig. 2). The bottom salinity ranged between 7 and 9 in the Baltic Proper (Data Sets 35 to 66 in the shallower habitat) and between 5 and 6 in the Bothnian Sea (data sets above 67 at the shallower stations and above 68 at the deeper stations).

The average temperatures at the sea bottom were between 3 and $8^{\circ} \mathrm{C}$. The water temperature is subject to strong seasonal fluctuations because mixing by wind and waves ventilates the water column. This mixing was obvious for the shallower habitat stations, where the variations were much more distinct than in the deeper habitat ones. Significantly lower average sea bottom temperatures were found in the Bothnian Sea.

The mean DO concentrations of all records were well above $4 \mathrm{ml} \mathrm{l}^{-1}$ (Fig. 2), although single measurements at a few stations showed values as low as $2 \mathrm{ml} \mathrm{l}^{-1}$. As these were always single values, the assumption that no station suffered from a severe lack of $\mathrm{O}_{2}$ was made. In the polyhaline transition area of the Belt Sea, Kiel 
Bay and Mecklenburg Bay, $\mathrm{O}_{2}$ deficiency seems to play a larger role in depths below $20 \mathrm{~m} . \mathrm{O}_{2}$ depletion is usually observed during calm summer conditions when the water body is stabilized by a strong thermocline (HELCOM 2003).

\section{$\alpha$-diversity}

The mean number of species per data set in both habitats was 18 (Table 3). The total number of species in the deeper habitat was higher than that in the shal-
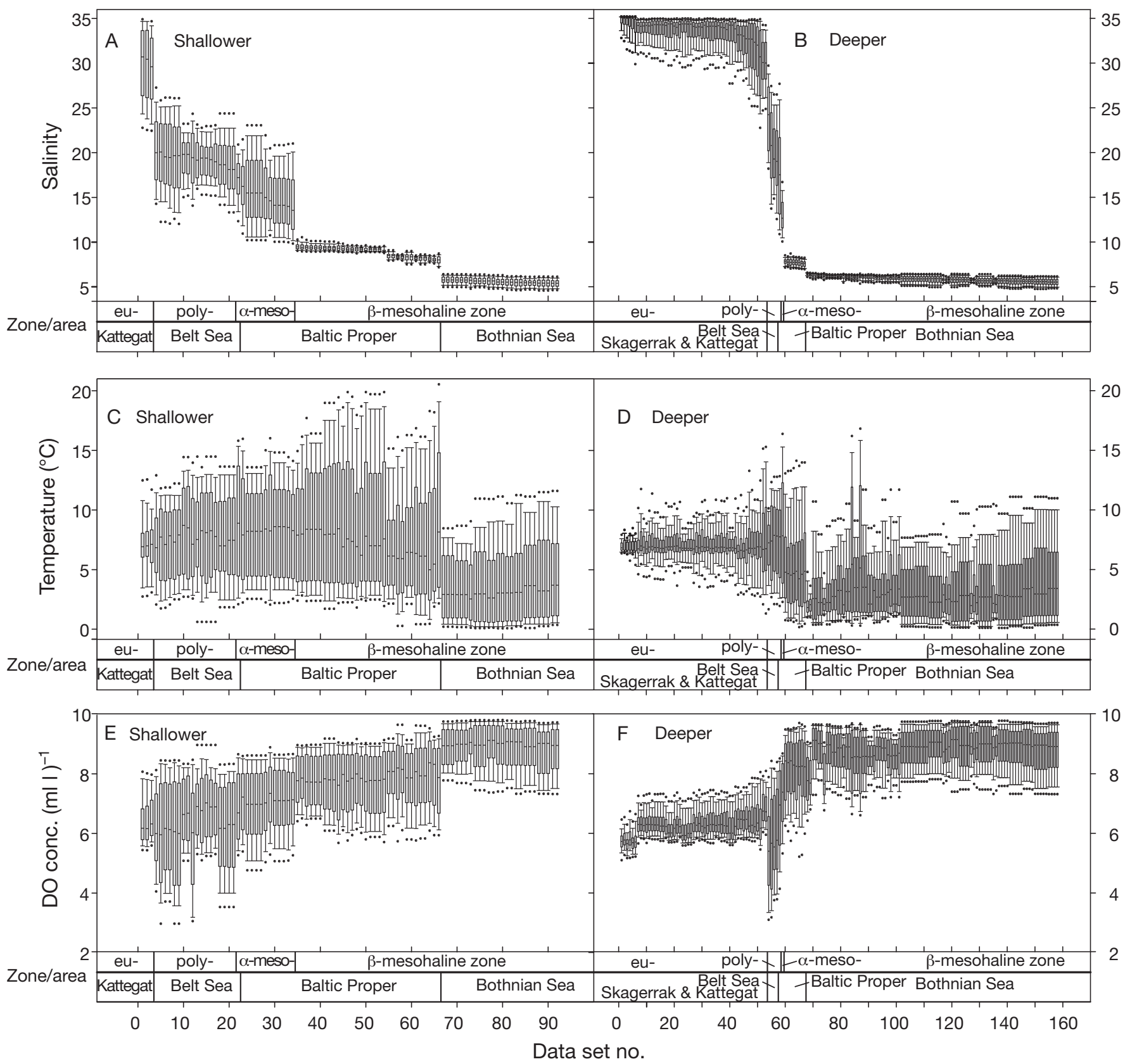

Fig. 2. Model $(A, B)$ salinities, $(C, D)$ temperatures, and $(E, F)$ dissolved oxygen $(D O)$ concentrations in the bottom water for $(A, C, E)$ shallower and $(\mathrm{B}, \mathrm{D}, \mathrm{F})$ deeper habitats derived from $5 \mathrm{~d}$ mean values generated with an adapted Modular Ocean Model MOM-3 numerical hindcast model for a 3 yr period before sampling (see 'Model data'). Data set numbers correspond to observations taken at the stations (Fig. 1), which were ranked according to their mean salinity and numbered in decreasing order shown from left to right. Data Set 1 corresponded to the data set with the highest mean salinity. For shallower habitats, Data Set 92 was the sample with the lowest mean salinity, while for deeper habitats Data Set 158 had the lowest mean salinity. Median values (horizontal line inside box), 25th and 75th percentiles (grey bars), 10th and 90th percentiles (error bars) and 5th and 95th percentiles (points) are shown. Zones were classified according to the Venice System (Caspers 1959), and areas of the Baltic Sea following Wallentinus (1991) 
lower habitat and was based on the higher number of euhaline data sets found in this habitat. As in the fully marine area the number of macrobenthic species is generally higher. Moreover, the more data sets there were, the more new rare species were discovered. The minimum number of species per data set (2 in shallower; one in deeper) occurred in areas with low salinities (5 to 6). Macrozoobenthos density varied greatly in both habitats (Table 3). Both the maximum and the minimum density values were found at salinities between 5 and 8 (i.e. the $\beta$-mesohaline area).

For both habitats, there was a linear relationship between salinity and number of species per data set (Fig. 3) and between salinity and diversity $H^{\prime}$ (shallower: $\mathrm{r}^{2}=0.63, \mathrm{p}<0.001$; deeper: $\mathrm{r}^{2}=0.77$, $\mathrm{p}<0.001$; data not shown). Species richness decreased in both habitats as salinity decreased.

A similar relationship was found on the level of the main taxonomic groups Mollusca, Polychaeta, and Crustacea. The linear relationship between number of species and salinity was most pronounced among the

Table 3. Species richness (no. of species), density (ind. $\mathrm{m}^{-2}$ ) and the corresponding salinities grouped in shallower habitats of 15 to $19 \mathrm{~m}$ in depth and deeper habitats of 20 to $35 \mathrm{~m}$ in depth

\begin{tabular}{|lcccc|}
\hline & \multicolumn{2}{c}{ Shallower } & \multicolumn{2}{c|}{ Deeper } \\
& $\mathrm{N}$ & Salinity & $\mathrm{N}$ & Salinity \\
\hline Species richness & & & & \\
Total & 172 & & 255 & \\
Mean (SD) & $18(15)$ & \multicolumn{3}{c}{$18(20)$} \\
Maximum & 60 & 20.3 & 79 & 34.3 \\
Minimum & 2 & 5.6 & 1 & $5.5-5.8$ \\
Density & & & & \\
Mean (SD) & $3378(3174)$ & & $2217(2132)$ & \\
Maximum & 13270 & 8.1 & 11564 & 6.3 \\
Minimum & 149 & 5.4 & 10 & 5.5 \\
\hline
\end{tabular}

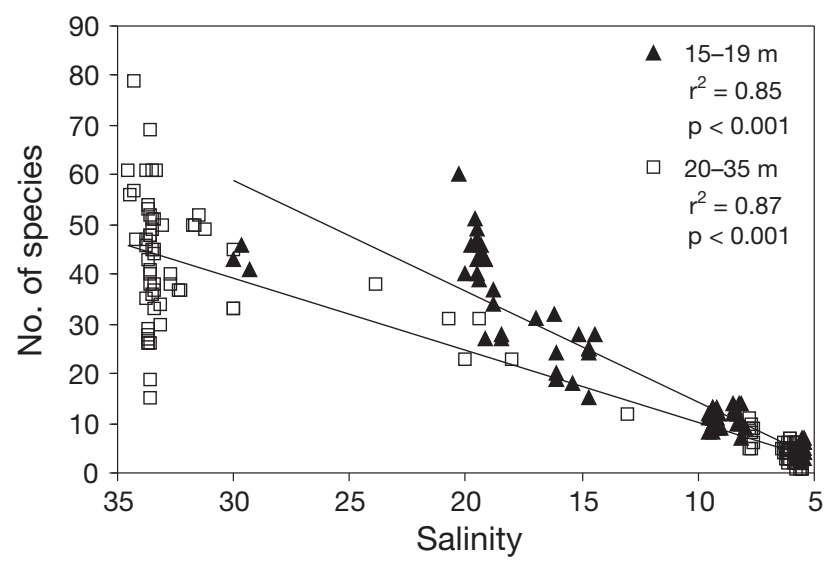

Fig. 3. Number of species versus mean salinity in the shallower and deeper habitats polychaetes, and slightly less so in the molluscs. Crustacean diversity was less related to salinity, and the decrease in number of species along the salinity gradient, especially in the shallower habitat, was also much lower (data not shown).

Additionally, there was a significant correlation between number of species and the number of replicates, but this correlation was consistently weaker than the correlation between species number and mean salinity.

\section{$\beta$-diversity}

For each habitat the $\beta$-diversity was calculated for all pairwise combinations of all taxonomic groups together and for each main taxonomic group (i.e. Mollusca, Polychaeta, and Crustacea) individually, and the results displayed as an MDS plot (Figs. 4 \& 5).

The nMDS plots of both habitats depict data sets with the same salinity close together (Fig. 4), suggesting that species turnover increased according to the salinity difference between data sets. In the MDS plots based on all $\beta$-diversities ( $\beta_{1-J}$ dissimilarities), data sets are located along the salinity gradient.

In the shallow habitat, the 3 data sets from the euhaline zone revealed high $\beta$-diversity values compared to those of the remaining data sets. The lowest dissimilarity to these 3 data sets was found in data sets from the polyhaline zone. The $\beta$-mesohaline data sets were set apart from all others, with a division into 2 salinity subgroups $(<8$ and $>8)$.

The accordance between the classification of data sets according to the Venice System and their $\beta$-diversities was significant. The species turnover in the deeper habitat showed a similar pattern (Fig. 4). The groups based on the Venice System were separated from each other. The ANOSIM test based on these groups yielded higher test values than in the shallower habitat, which could be related to only a few records being available from polyhaline zones, and only one from the $\alpha$-mesohaline zone.

Looking at the 3 major taxonomic groups Mollusca, Polychaeta and Crustacea separately, a similar trend was visible for both habitats (Fig. 5). In the Mollusca and Polychaeta, data sets from the euhaline zone were separated from those of all the others. Furthermore, a directional relationship along the salinity gradient was obvious.

In the Crustaceans, the diversity levels at some euhaline data sets were obviously different in both habitats from those at all the other data sets. At 3 euhaline data sets in the shallower habitat only Ampelisca brevicornis, A. tenuicornis and Hyala vitrea were found. At one euhaline data set in the deeper habitat, only Pagurus bernhardus was found. When these 'outliers' were 

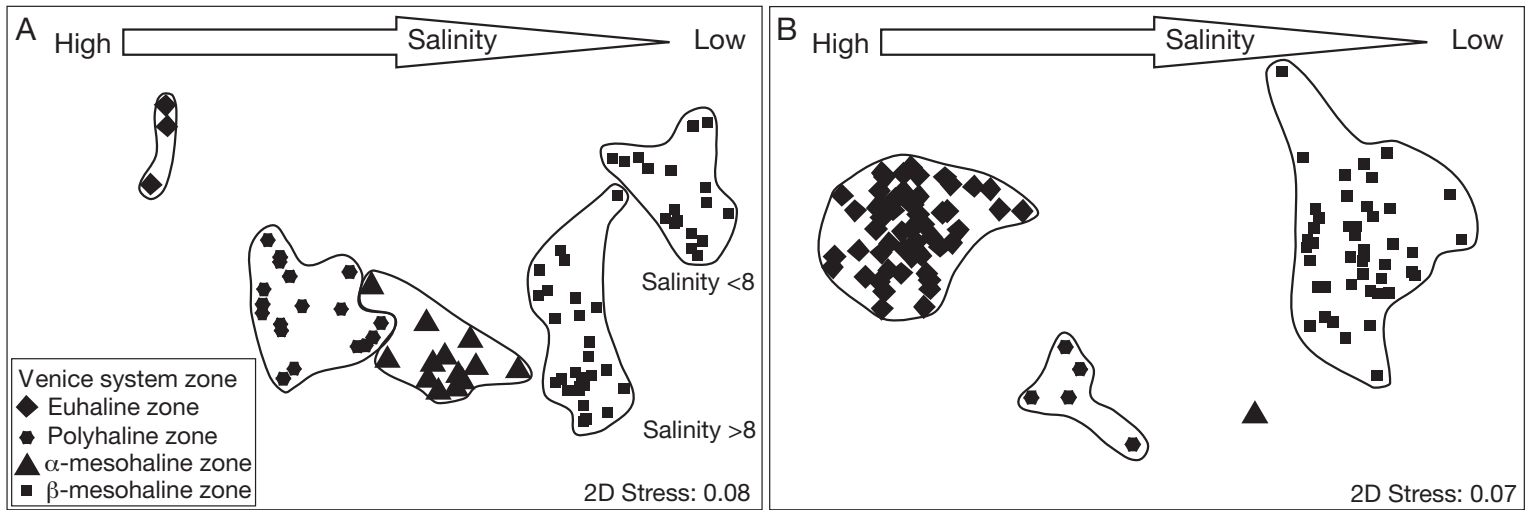

Fig. 4. Non-metric MDS plots of macrofauna community structure on the basis of presence-absence data and Jaccard dissimilarities between all pairs of data sets for (A) shallower and (B) deeper habitats. The significance of Venice System zone groupings was tested with a 1-way ANOSIM (shallower: $r=0.727, p<0.001$; deeper: $r=0.99, p<0.001$ )

removed, the result was similar to that in the other main taxonomic groups.

A SIMPER analysis was carried out on the basis of the $\beta_{B C}$ indices of the presence-absence data. As in the previous MDS analyses, samples were grouped into classes (1 through 4) according to the salinity classes of the Venice System; 6 additional classes (5 through 10) were included to account for between-class comparisons. Mean Jaccard dissimilarities $\left(\beta_{1-J}\right)$ indices for these 10 classes were also calculated. The Bray-Curtis dissimilarity indices $\left(\beta_{B C}\right)$ always yield lower values than $\beta_{1-J}$ ones and are identical to values of Whittaker's beta $\left(\beta_{W}\right.$, Whittaker 1972) when calculations are carried out using the presence-absence data.

The SIMPER analysis revealed that the mean species turnover within each salinity class was much lower than that between classes. This result applied to both habitats and both $\beta$-diversity indices. The mean species turnover $\left(\beta_{B C}\right)$ within the classes lay between 33 and $48 \%\left(\beta_{1-J}=52\right.$ to $\left.62 \%\right)$ in the shallower habitat and between 35 and $51 \%\left(\beta_{1-J}=51\right.$ to $\left.65 \%\right)$ in the deeper habitat. Notably higher was the species turnover $\left(\beta_{B C}\right)$ between the classes, which lay between 57 and $99 \%$ $\left(\beta_{1-J}=75\right.$ to $\left.100 \%\right)$ in the shallower habitat and between 69 and $99 \%\left(\beta_{1-J}=81\right.$ to $\left.100 \%\right)$ in the deeper habitat. The species turnover along the salinity gradient was somewhat lower between the polyhaline and the $\alpha$-mesohaline zones (Class 6 ) in both habitats. The highest mean species turnover between adjacent zones was found between the euhaline and polyhaline zone (Class 5) at a salinity of about 30.

The SIMPER analysis was repeated for the 3 main taxonomic groups (Crustacea, Mollusca and Polychaeta) (Fig. 6). Data sets that had no records of species from the respective main groups were removed from the analysis. As described above in relation to the complete presence-absence data, when all the species were taken into account, the $\beta$-diversities within the salinity zones were smaller than between the zones. The crustaceans exhibited higher species turnover within and between classes than molluscs and polychaetes did. The molluscs, represented mainly by the long-lived bivalve species, showed a tendency towards lower species turnover.

On the basis of the $\beta_{1-J}$ values of the presenceabsence data, all possible single $\beta$-diversities between the data sets were assigned to the 10 classes (Figs. 6 \& 7). Statistical analyses revealed highly significant differences between $\beta$-diversities within the salinity classes (Classes 1 to 4 ) and between classes (Classes 5 to 10$)$ in both habitats $(\mathrm{p}<0.001)$. Species turnover increased to almost $100 \%$ as salinity differences between the classes increased, which meant an almost complete change in community composition between the euhaline and the $\beta$-mesohaline zones (Class 9). All pairwise comparisons between adjacent salinity classes (i.e. Classes 5 to 7) and between classes being geographically further apart (i.e. Classes 8 to 10, except Class 8 vs. 10 in the shallower habitat) also revealed significant differences in both habitats (Mann-Whitney test, Bonferroni's correction, p < 0.05). Pairwise comparisons within salinity classes showed significant differences for Classes 2 to 4 in the shallower habitat and Class 1 vs. 2 and Class 1 vs. 4 in the deeper habitat. In addition, $\beta$-diversity within the $\beta$-mesohaline zone fluctuated significantly, indicating that other factors apart from salinity affect $\beta$-diversity in this area.

\section{Hydrographic and spatial distance correlations with $\beta$-diversity}

Table 4 shows the correlation coefficients of the RELATE (2STAGE) analyses. Values of more than 0.8 


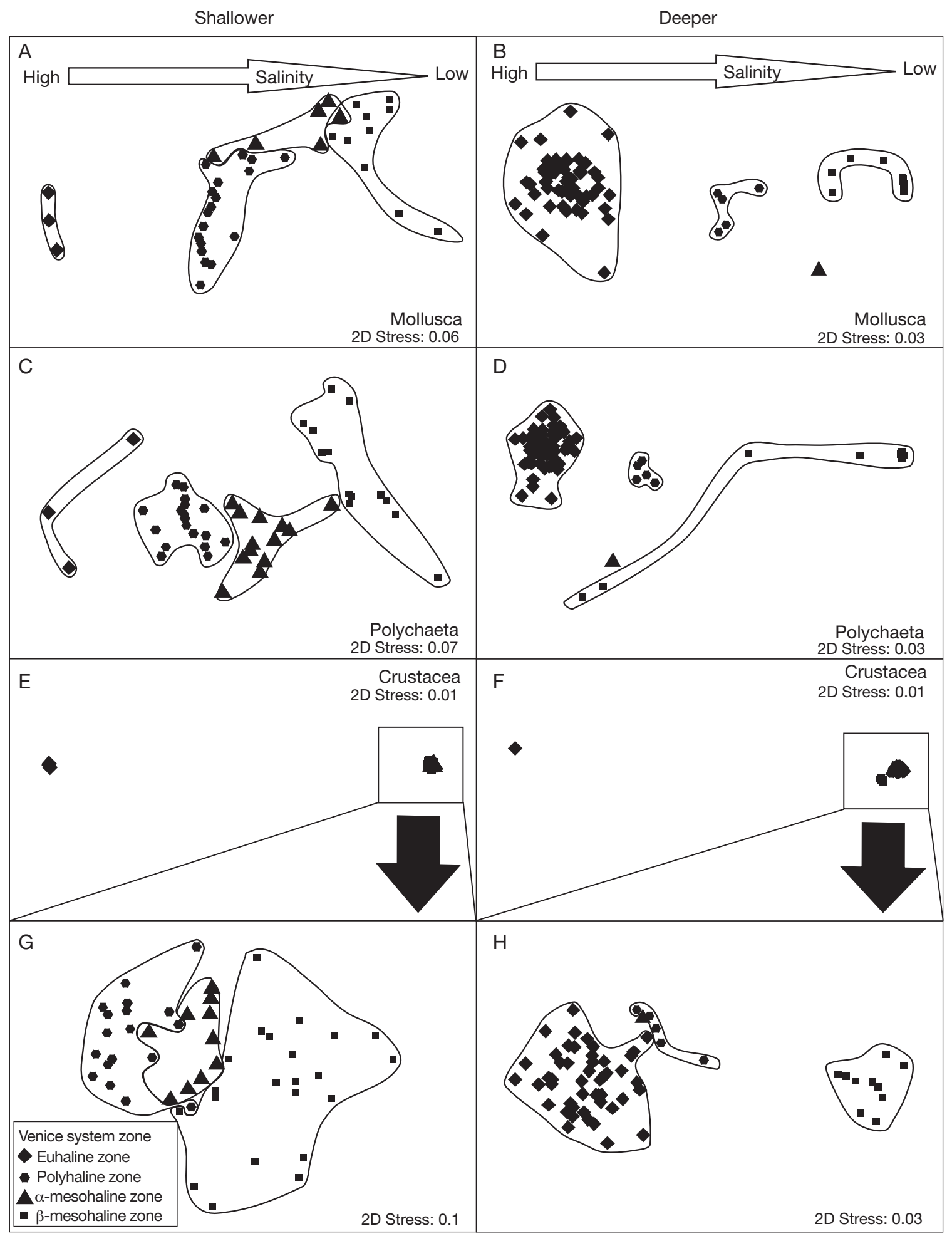

Fig. 5. Mollusca, Polychaeta, and Crustacea. nMDS plot showing Jaccard dissimilarities of the 3 major taxonomic groups, (A,B) Mollusca, $(C, D)$ Polychaeta and $(E-H)$ Crustacea, determined on the basis of presence-absence data for data sets in (A,C,E) shallower and $(B, D, F)$ deeper habitats. Data sets with no taxa in these groups (mostly mesohaline data sets) were excluded. The significance of Venice System zones was tested within each group with a 1-way ANOSIM test (Mollusca: shallower: $r=0.648, p<$ 0.001, deeper: $r=0.97, p<0.001$; Polychaeta shallower: $r=0.778, p<0.001$, deeper: $r=0.859, p<0.001$; Crustacea shallower: $r=$ $0.491, \mathrm{p}<0.001$, deeper: $\mathrm{r}=0.885, \mathrm{p}<0.001)$. For the Crustacea in both habitats, additional MDS plots excluding some euhaline data sets are shown $(\mathrm{G}, \mathrm{H})$ 

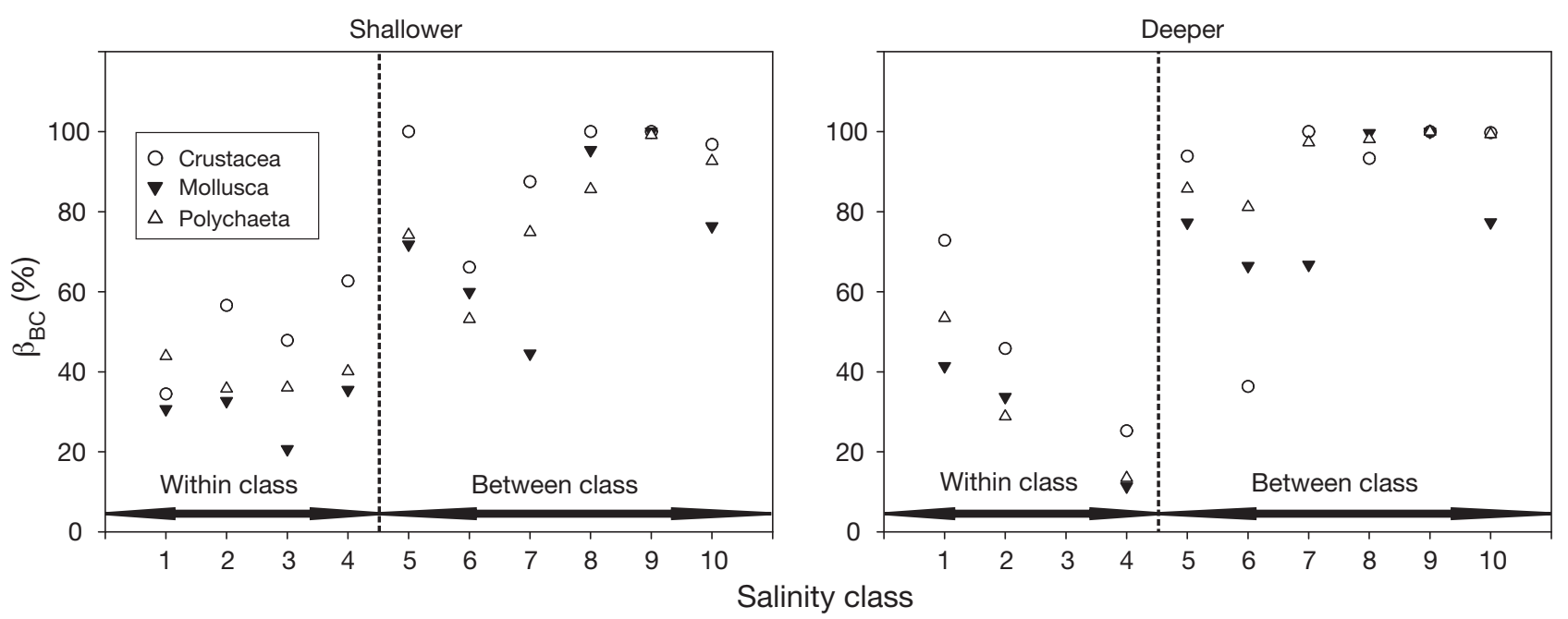

Fig. 6. Mollusca, Polychaeta, and Crustacea. Mean $\beta$-diversity indices $\left(\beta_{B C}\right)$ of the 3 main taxonomic groups within and between salinity classes of the Venice System. C1: within euhaline zone salinity class; C2: within polyhaline zone class; C3: within $\alpha$-mesohaline zone class; $\mathrm{C} 4$ : within $\beta$-mesohaline zone class; C5: euhaline vs. polyhaline zone class; C6: polyhaline vs. $\alpha$-mesohaline zone class; C7: $\alpha$-mesohaline vs. $\beta$-mesohaline zone class; C8: euhaline vs. $\alpha$-mesohaline zone class; C9: euhaline vs. $\beta$-mesoha line zone class; $\mathrm{C} 10$ : polyhaline vs. $\beta$-mesohaline zone class
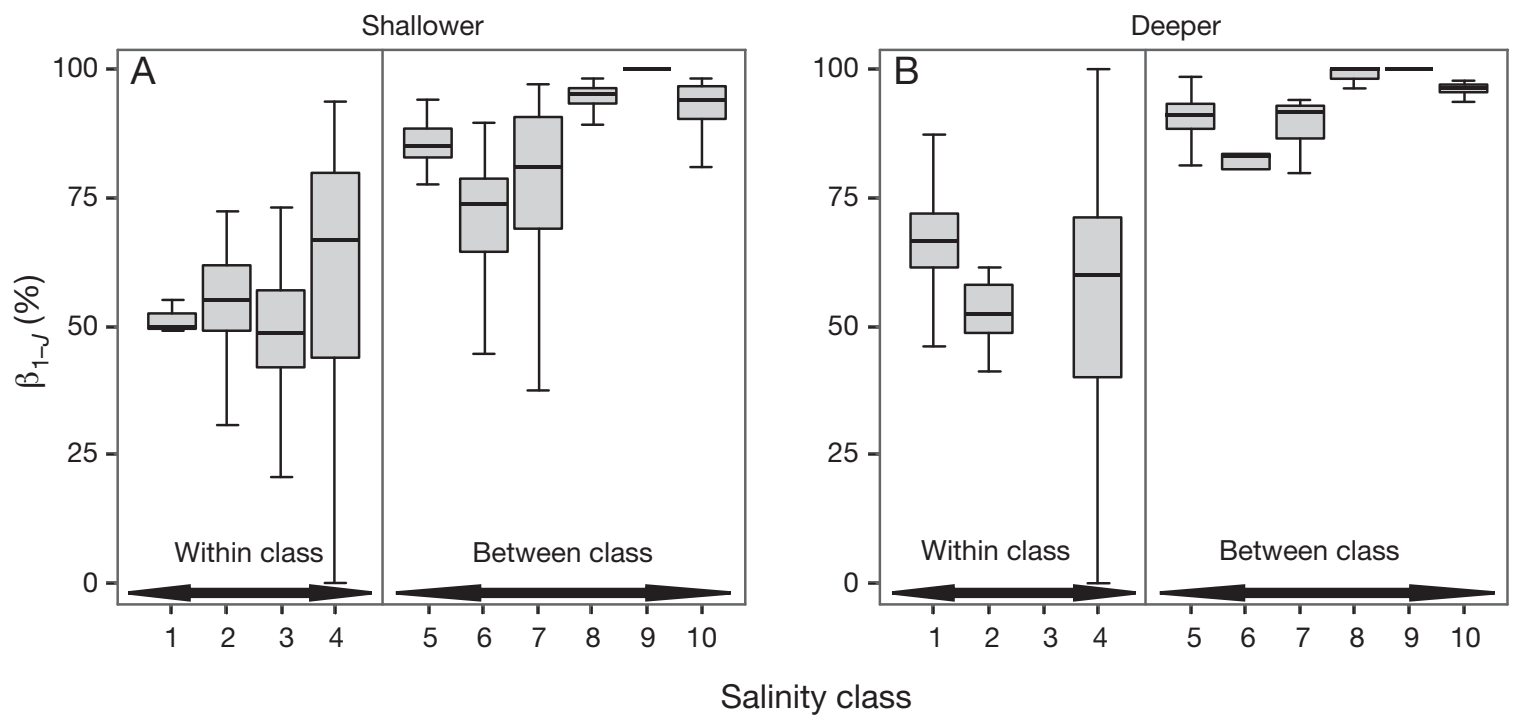

Fig. 7. Complementarities $\left(\beta_{1-J}\right)$ of all taxa within and between salinity classes of the Venice System for (A) shallower and (B) deeper habitats. Median values (horizontal line inside box), 25th and 75th percentiles (grey box) and all values in between 1.5 times the inter-quartile distance (error bars) are shown. See Fig. 6 legend for class descriptions

were calculated for $\beta_{1-J}$ vs. average salinity (shallower: $\rho=0.88$; deeper: $\rho=0.86$ ), minimum salinity (shallower: $\rho=0.85$; deeper: $\rho=0.87$ ), maximum salinity (shallower: $\rho=0.81$; deeper: $\rho=0.83$ ), mean DO concentration (shallower: $\rho=0.83$; deeper: $\rho=0.80$ ) and maximum DO concentration (deeper: $\rho=0.82$ ).

Many variables were strongly correlated with mean salinity (Table 4). For the shallower habitat these factors were corrected spatial distance, maximum salinity, minimum salinity, fluctuation of salinity, mean DO con- centration, and maximum DO concentration. For the deeper habitat corrected spatial distance, maximum salinity, minimum salinity, fluctuation of salinity, mean temperature, minimum temperature, mean DO concentration, and maximum DO concentration were strongly correlated with mean salinity. We tested whether mean salinity was the main factor describing species turnover by performing a BIOENV test, which shows the variable(s) that best describe the patterns of the resemblance matrix. BIOENV was performed with all factors 
Table 4. Results of RELATE (2STAGE) analyses showing Spearman correlations ( $\rho$ ) between $\beta$-diversity indices ( $\left.\beta_{1-J}\right)$, corrected spatial distances and hydrographic factors salinity, temperature, oxygen concentration of samples in (A) shallower (15 to $19 \mathrm{~m}$ ) and (B) deeper $(20$ to $35 \mathrm{~m}$ ) habitats. $\rho$ values $>0.5$ are significant correlations at $p \leq 0.01$. Bold: correlations $>0.8$

\begin{tabular}{|c|c|c|c|c|c|c|c|c|c|c|c|c|c|}
\hline & \multirow[t]{2}{*}{$\beta_{1-J}$} & \multirow{2}{*}{$\begin{array}{c}\text { Spatial } \\
\text { distance } \\
\text { (m) }\end{array}$} & \multicolumn{4}{|c|}{$\longrightarrow$ Salinity -} & \multicolumn{4}{|c|}{$\begin{array}{c}\text { Temperature }- \\
\left(\mathrm{ml} \mathrm{l}^{-1}\right)\end{array}$} & \multicolumn{3}{|c|}{ DO conc. } \\
\hline & & & Mean & Max & Min & Range & Mean & $\operatorname{Max}$ & Min & Range & Mean & Max & Min \\
\hline \multicolumn{13}{|l|}{ (A) Shallower habitats } & \\
\hline \multicolumn{14}{|l|}{ Salinity } \\
\hline Mean & 0.88 & 0.68 & & & & & & & & & & & \\
\hline Max & 0.81 & 0.69 & 0.93 & & & & & & & & & & \\
\hline Min & 0.86 & 0.78 & 0.86 & 0.76 & & & & & & & & & \\
\hline Range & 0.55 & 0.37 & 0.74 & 0.84 & 0.47 & & & & & & & & \\
\hline \multicolumn{14}{|l|}{ Temperature $\left({ }^{\circ} \mathrm{C}\right)$} \\
\hline Mean & 0.51 & 0.78 & 0.32 & 0.36 & 0.50 & 0.05 & & & & & & & \\
\hline Max & 0.20 & 0.31 & 0.12 & 0.17 & 0.12 & 0.09 & 0.45 & & & & & & \\
\hline Min & 0.38 & 0.47 & 0.32 & 0.34 & 0.47 & 0.20 & 0.46 & 0.12 & & & & & \\
\hline Range & 0.13 & 0.17 & 0.10 & 0.13 & 0.05 & 0.12 & 0.27 & 0.88 & 0.04 & & & & \\
\hline \multicolumn{14}{|c|}{ DO concentration $\left(\mathrm{ml} \mathrm{l}^{-1}\right)$} \\
\hline Mean & 0.83 & 0.82 & 0.81 & 0.84 & 0.78 & 0.59 & 0.64 & 0.30 & 0.40 & 0.22 & & & \\
\hline $\operatorname{Max}$ & 0.75 & 0.72 & 0.72 & 0.72 & 0.77 & 0.46 & 0.55 & 0.15 & 0.53 & 0.12 & 0.81 & & \\
\hline Min & 0.52 & 0.54 & 0.53 & 0.62 & 0.45 & 0.51 & 0.42 & 0.24 & 0.20 & 0.23 & 0.75 & 0.52 & \\
\hline Range & 0.39 & 0.34 & 0.42 & 0.49 & 0.32 & 0.44 & 0.24 & 0.15 & 0.11 & 0.18 & 0.55 & 0.37 & 0.88 \\
\hline \multicolumn{14}{|l|}{ (B) Deeper habitats } \\
\hline \multicolumn{14}{|l|}{ Salinity } \\
\hline Mean & 0.86 & 0.82 & & & & & & & & & & & \\
\hline Max & 0.83 & 0.81 & 0.87 & & & & & & & & & & \\
\hline Min & 0.87 & 0.76 & 0.92 & 0.82 & & & & & & & & & \\
\hline Range & 0.75 & 0.74 & 0.72 & 0.73 & 0.73 & & & & & & & & \\
\hline \multicolumn{14}{|l|}{ Temperature $\left({ }^{\circ} \mathrm{C}\right)$} \\
\hline Mean & 0.72 & 0.79 & 0.74 & 0.75 & 0.71 & 0.65 & & & & & & & \\
\hline Max & 0.13 & 0.12 & 0.16 & 0.15 & 0.12 & 0.12 & 0.11 & & & & & & \\
\hline Min & 0.67 & 0.61 & 0.78 & 0.65 & 0.76 & 0.61 & 0.49 & 0.17 & & & & & \\
\hline Range & 0.34 & 0.29 & 0.42 & 0.34 & 0.36 & 0.28 & 0.23 & 0.81 & 0.48 & & & & \\
\hline \multicolumn{14}{|c|}{ DO concentration $\left(\mathrm{ml} \mathrm{l}^{-1}\right)$} \\
\hline Mean & 0.80 & 0.88 & 0.88 & 0.85 & 0.81 & 0.73 & 0.81 & 0.14 & 0.73 & 0.36 & & & \\
\hline Max & 0.82 & 0.77 & 0.91 & 0.81 & 0.88 & 0.71 & 0.67 & 0.13 & 0.87 & 0.40 & 0.86 & & \\
\hline Min & 0.43 & 0.65 & 0.54 & 0.56 & 0.45 & 0.46 & 0.56 & 0.15 & 0.34 & 0.19 & 0.63 & 0.44 & \\
\hline Range & 0.26 & 0.34 & 0.29 & 0.24 & 0.28 & 0.25 & 0.22 & 0.22 & 0.23 & 0.27 & 0.31 & 0.27 & 0.43 \\
\hline
\end{tabular}

and also with the exclusion of all factors that were strongly correlated with mean salinity.

For the shallower habitat, mean salinity was the factor that best described $\beta$-diversity $(\rho=0.88 ; p \leq 0.01)$ and for the deeper habitat, mean salinity and minimum salinity together were the factors that best described $\beta$-diversity ( $\rho=0.875 ; p \leq 0.01$ ). Furthermore, following the RELATE (2STAGE) test results, mean salinity was also strongly correlated to minimum salinity in the deeper habitat.

The main factors contributing to $\beta$-diversity (i.e. species turnover) in the Baltic Sea were mean and minimum salinity. Maximum salinity and DO concentration in the bottom water may also play a role, as may the spatial distance between stations (shallower: $\rho=$ 0.75; deeper: $\rho=0.77$ ). Also the mean and minimum temperature seemed to play a role, but only in the deeper habitat.

\section{DISCUSSION}

\section{Methodological considerations}

Regional effects

In terms of salinity and the degree of connection to the open marine sea, the Baltic Sea can be divided into 2 areas. The first includes the western Baltic Sea to the Darss Sill and is characterized by high salinity and high salinity fluctuations. This area is connected to the open sea via the Kattegat and Skagerrak. The high number of species found in this area results mainly from inflow events that carry larval stages and juveniles of benthic invertebrates. In the marine environment, planktonic larval stages dominate (Udalov et al. 2004). Most marine polychaetes and molluscs are recruited via pelagic larval stages. Though the major- 
ity of these specimens can exist at lower salinities as an adult, they cannot reproduce under such conditions. The distribution of many species therefore depends on whether inflow events and the occurrence of larval stages coincide. The extreme salinity variations found in the western Baltic Sea appear to be no problem for the fauna present. The species found here are either good osmoregulators or protect themselves against extreme salinity values by burrowing (polychaetes, crustaceans and molluscs) or closing their shells (molluscs) (Teske \& Wooldridge 2004).

The second area covers the region east of the Darss Sill, where both the salinity and the variation in salinity are much lower. Moreover, due to the Darss Sill, a direct connection to the open North Sea no longer exists. The relative seclusion of this area impedes the dispersal of marine species. With salinities between 5 and 8, this area is brackish and provides an environment that only a few specialists can inhabit (Remane 1934). Most of these benthic organisms have no pelagic larval stages and direct benthic development prevails (Udalov et al. 2004), which means that options for dispersal are limited. Most species are incapable of generating the high energy levels required for osmoregulation in addition to those needed to maintain their vital functions. This limitation is particularly true of freshwater fauna and leaves freshwater species with little chance of colonizing the brackish water. Another explanation for the low number of species at salinities between 5 and 8 is the low immigration potential that the Baltic Sea offers to invading species (Deaton \& Greenberg 1986 and references cited therein).

Implications to sampling design

As a general rule, sampling performed with a small sized grab and a low number of replicates has a tendency to result in species richness being underestimated. Rumohr et al. (2001) discovered for the western Baltic Sea that only $53 \%$ of the species found in 70 replicates are found in 5 replicates. The same authors also discuss the problem of rare species (singletons) but conclude that the exclusion of singletons leads to an unacceptable loss of ecological information and is therefore not admissible practice in biodiversity studies. Accordingly, no singletons were excluded from our data sets.

Because of the limited surface area and varying number of replicates, the species lists of some stations may not reflect the actual total species numbers in the respective areas. This effect was analyzed in a study by Powilleit et al. (1995) in the Pomeranian Bay (Southern Baltic), an area where the expected number of species was $<20$. The authors calculated that $30.0025 \mathrm{~m}^{2}$ sub- samples are necessary to find $80 \%$ of the species present. In areas with species numbers $>20,5$ sub-samples $\left(0.0025 \mathrm{~m}^{2}\right)$ should be taken. On the basis of these findings, one replicate with a surface area of $0.1 \mathrm{~m}^{2}$ per sampling site (e.g. all samples from the Bothnian Sea, Table 2), seemed to be sufficient in locations east of the Darss Sill (Polish and Lithuanian coast and up to southern Sweden in the Stockholm area in the Baltic Proper) characterized by low species richness. As these stations are located in a salinity range with minimum species numbers (Remane 1934) and the composition of the macrofauna communities is very homogeneous, underestimation might not be a critical factor (e.g. Kotta et al. 2007).

The number of replicates is most critical in the transition zone to the North Sea where the number of singletons is mostly high, which may have led to higher species turnover in cases where data sets with different numbers of replicates are compared.

At low total species numbers the exchange of a few species may result in high $\beta$-diversities. The absence of 2 species raised $\beta_{1-J}$ between Data Sets 70 and 76 from the deeper habitat to $40 \%$, for example. This exchange may explain the significantly higher mean species turnover and high variability within the $\beta$-mesohaline zone (Fig. 7).

\section{Dependency of species richness ( $\alpha$-diversity) on salinity}

The number of marine invertebrate taxa changed rapidly between the Kattegat (some 850 macroscopic animal species) and the Baltic proper (around 80), the Bothnian Sea (around 50) and the innermost Bothnian Bay $(<10)$ (Leppäkoski \& Olenin 2000). A study by Josefson (2009) shows that the species number increases by a factor of 10 between salinities of 10 and 33. In the Pomeranian Bay, where salinity ranges between 6 and 10, Powilleit et al. (1995) found 20 taxa in the period from 1993 to 1994. The species number drops between the Southern Baltic (10 to 11 taxa per $0.1 \mathrm{~m}^{2}$ sampling unit) and the Northern Baltic Proper (less than 8 taxa per sampling unit) until fewer than 2 taxa per sampling unit are found in Bothnian Bay (Leppäkoski et al. 2002).

Our results agreed with other findings and showed that the decline in salinity is the main factor in the decreasing species richness across the Baltic Sea (e.g. Josefson \& Hansen 2004, Josefson 2009). Similarly, decreasing numbers of species in both the habitats studied support the salinity dependence of $\alpha$-diversity. The mean numbers of species at the various salinities are on the same level for both habitats. We found strong evidence that species richness increased sig- 


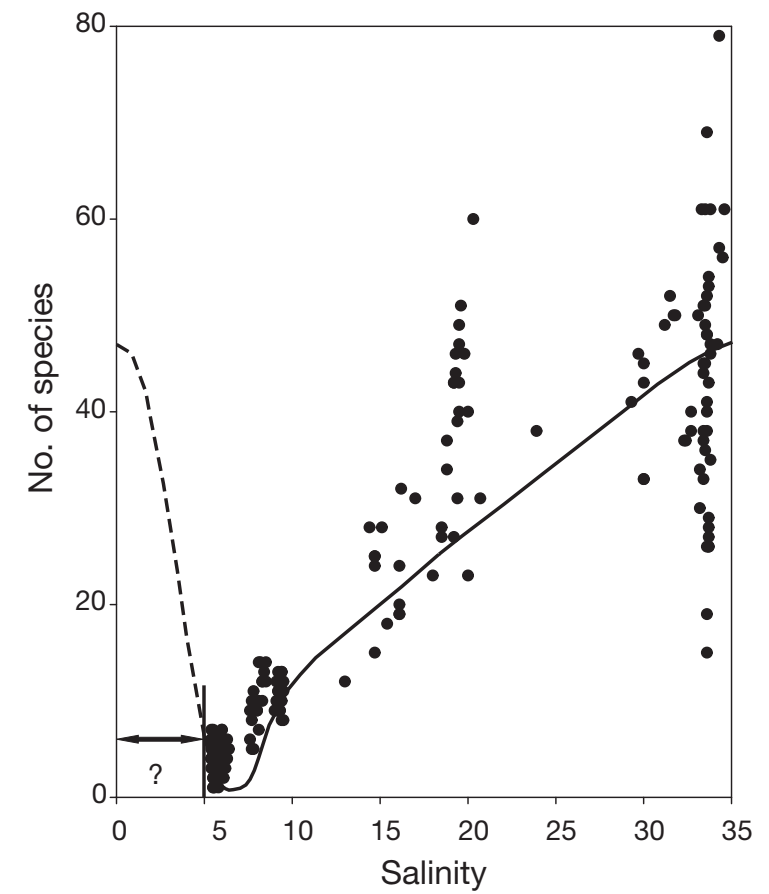

Fig. 8. Number of species vs. mean salinity for all data sets from both habitats overlaid onto the predicted 'Remane curve' (solid line, adapted according to Remane 1934). The curve was fitted to the minimum number of species at salinities between 5 and 8 and to the regression line through all points. The part of the curve for salinities below 5 is hypothesized (dashed line)

nificantly below a salinity of 3, mainly through supervening/accessory freshwater taxa such as insects (i.e. chironomids and trichoptera) and oligochaetes (Meriläinen 1984, Perus \& Bonsdorff 2004, Piscart et al. 2005, Berezina et al. 2009). No stations were available for such low salinity areas in this study.

The original 'Remane curve' (Remane 1934, 1958) refers neither to a particular community, such as benthic invertebrates, nor to specific habitat characteristics and is more to be regarded as a scheme. We therefore redraw this relationship more precisely by incorporating all of the data sets used in this study to create a new curve of species number against salinity (Fig. 8).

As in the original 'Remane curve', the minimum species number was found between salinities of 5 and 8 . The highest species number was found at salinities around 34. Since no samples were available from salinities ranging from 0 to 5 in this study, only hypothetical points can be plotted for this part of the curve. Fig. 8 shows some variations in species numbers in the salinity ranges 18 to 20 and 33 to 35 . Reasons for these variations might be that both salinity ranges stand in the transition area between 2 salinity classes or that the presence or absence of a species can be driven by only small salinity fluctuations. In our study we used data sets from $11 \mathrm{yr}$, so interannual variation of the fauna might be another factor for the observed variations. Disturbance of the benthic community by other factors, which were not measured, could also be a reason. Large variations were found mostly in the deeper habitat, where undocumented $\mathrm{O}_{2}$ deficiency might be an additional reason.

\section{Species turnover $(\beta$-diversity)}

Indices used in $\beta$-diversity studies

Many recent studies take the approach that $\beta$-diversity is a measure of heterogeneity. They calculate the $\beta$-diversities of larger areas and compare these with other areas (Gray 2000, Ellingsen 2002, Ellingsen \& Gray 2002). In these studies, $\beta$-diversity is regarded as a measure of species richness. The higher the species turnover of a region, the higher the species richness of the area will be (Shin \& Ellingsen 2004).

However, $\beta$-diversity can be a measure of species turnover in an area as well as a measure of diversity or heterogeneity (Novotny \& Weiblen 2005). The species turnover approach is used in the present study along an environmental gradient. In this case, the use of $\beta$ diversity as a measure of species turnover facilitates the detection of patterns (e.g. boundaries) of higher or lower species turnover along a gradient. High species turnover and thus a high $\beta$-diversity value is expected where the environmental factor, which is the basis of the gradient between 2 compared data sets, exceeds a critical value for a large number of organisms. Legendre et al. (2005) argued that if differentiation among sites is due to environmental factors, $\beta$-diversity should be analyzed with regard to the hypothesized forcing variables. One difficulty posed by this approach is that of excluding the influence of other possible gradients such as depth, temperature, total phosphorus, $\mathrm{O}_{2}$ saturation, sediment type, sediment organic values and spatial distance (e.g. Gaston et al. 1998, Perus \& Bonsdorff 2004).

In this study, $\beta$-diversity corresponded to the percentage of species turnover between 2 data sets along a gradient of average salinity. Based on this definition the question arises as to which of the indices used so far best expresses the species turnover. Some studies use the Jaccard (dis)similarity index as a measure of species turnover (e.g. Izsak \& Price 2001, Condit et al. 2002, Anderson et al. 2006, Ferreira \& Petrere 2009, Terlizzi et al. 2009). Boyce \& Ellison (2001) found that the Jaccard index resulted in consistently high rank and linear correlation to their data, so this index is therefore one of the best-performing (dis)similarity indices. Vellend (2001) recommends the Sørensen sim- 
ilarity index $\left(S_{S}\right)$ for presence-absence data as the best way of calculating species turnover. The complement of the Sørensen index yields the same values as the Bray-Curtis (dis)similarity index $\left(\beta_{B C}\right)$ with presenceabsence data. Furthermore, the Jaccard index is related to the Sørensen index by $J=S_{s}\left(2-S_{S}\right)$, and the complement of the Jaccard index is $\beta_{1-J}=1-J$.

The Bray-Curtis index has been used in several recent studies, including those by Mumby (2001) and Anderson et al. (2006). Since the Bray-Curtis index is the standard index for the resemblance measure in the PRIMER package, it is widely used for community analyses such as cluster analysis or MDS. Nevertheless, the Jaccard index $\left(\beta_{1-J}\right)$ is considered here to be the most meaningful $\beta$-diversity index. $\beta_{1-J}$ provides values approximately proportional to $\beta_{B C}$ but slightly higher, which should be taken into consideration when the 2 indices are compared.

In this study, the comparisons within salinity classes were calculated using data sets from different stations and from the same station in different years. We are aware of this problem and performed separate calculations to exclude comparisons of data sets from the same station (i.e. different years). This consideration resulted in negligible differences in mean $\beta$-diversities.

\section{Comparison to other studies}

No study of species turnover along the entire salinity gradient of the Baltic Sea has yet been published, but Josefson \& Hansen (2004) and Josefson (2009) examined species turnover in the transition zone between the North Sea, the Skagerrak and Kattegat, and the Belt Sea. They showed that species turnover is higher in crustaceans than in polychaetes and molluscs, and conclude that crustacean distribution is rather limited. This pattern was confirmed by the present study. Giberto et al. (2007), who investigated the species turnover along a salinity gradient in the Rio de la Plata estuary, found that the highest $\beta$-diversity values occurred in the transition zones between the freshwater and estuarine environments and between the estuarine and marine environments. The $\beta$-diversities $\left(\beta_{w}\right)$ within each of these 3 zones ranged from 20 to $70 \%$, whereas the $\beta$-diversities between these zones were always above $90 \%$. In this particular study the polychaetes dominated (22 species), followed by the molluscs and then the crustaceans (18 and 15 species, respectively). Here too, the highest species turnover was found for crustaceans in the freshwater and estuarine environments. In the Rio de la Plata estuary, species turnover increases as spatial distance and salinity does. There was a significant correlation between spatial distances and salinities.
Greenwood (2007) performed a community analysis of nekton communities along a salinity gradient in Florida and found a clear change along this gradient, identifying cluster groups at levels of species turnover of more than 60 to $65 \%$. A study by Piscart et al. (2005) along a salinity gradient from 0.2 to 2.6 in a French river revealed $\beta_{1-J}$ values ranging from 20 to $33 \%$. The main taxonomic group there was aquatic insects. The results of the present study also showed differences in species turnover between the main taxonomic groups. A single taxonomic group (e.g. crustaceans) does not necessarily reflect the typical species turnover in one area (Ellingsen \& Gray 2002).

\section{Effect of climate change}

The BALTEX Assessment of Climate Change for the Baltic Sea Basin (BACC) team stated that the average salinity of the Baltic Sea is projected to decrease between 8 and $50 \%$ by the end of the 21st century (BACC author team 2008). This decrease will have major influence on the faunal distribution. Many marine invertebrates have a lower limit to their salinity tolerances, e.g. salinity of 2 for Gammarus locusta, 3 for Corophium volutator, 5.5 for Idotea baltica, 6 for Pontoporeia femorata and Harmothoe sarsi, 7 for Pygospio elegans and Laomedea lovéni, and 7.5 for Terebellides stroemii and Fabricia sabella. Thus along the salinity gradient of the Baltic Sea we expect a geographical shift of the salinity regime and a decrease in species richness first occurring in the northern Baltic Sea. The retreat of less tolerant benthic fauna towards the south has already begun, for example, in the polychaete Scoloplos armiger. On the other hand, freshwater species might become more dominant, and invaders from warmer seas such as the zebra mussel Dreissena polymorpha might enlarge their distribution area (BACC 2008). According to an expected shift in the salinity regime in the Baltic Sea, the locations of high and low $\beta$-diversities might change too, and the monitoring of $\beta$-diversity may become a useful tool to document these changes.

\section{Verification of the Venice System}

The 'Venice System' was recommended for universal application at the 1958 symposium on the classification of brackish waters (Caspers 1959, den Hartog 1964). Today it is generally accepted (Chainho et al. 2007, Greenwood 2007) and was applied, for example, in the classification of the Baltic Sea coastal waters under the EU Water Framework Directive (European Union 2000, von Weber 2004). 
According to Chainho et al. (2006), 2 types of estuaries exist: homiohaline and poikilohaline. Homiohaline estuaries are characterized by relatively constant salinity gradients, while poikilohaline estuaries are subject to strong salinity fluctuations (e.g. river estuaries). The Baltic Sea can be classified as a homiohaline estuary, especially east of the Darss Sill. Because of relatively minor salinity variations at the stations there, they can easily be assigned to distinct salinity zones, and the Venice-System can be applied without modification (Chainho et al. 2006).

The Venice System is based on boundaries set using mean salinity. However, as other factors such as salinity variation (the range between maximum and minimum salinity values) might be responsible for the distribution of species, systems based on average salinities may only inadequately reflect the real distribution limits (den Hartog 1964, Attrill 2002). A classification system that is based on the correlation between a biocoenosis and average salinity is, therefore, never completely accurate (den Hartog 1964). In our study we found high correlations between species composition and the mean and minimal salinity values.

The large annual salinity variations between 10 and 25 that occur in the western Baltic (Fig. 2) lead to a lack of stenohaline species, as these species are adapted to a constricted salinity range. In the case of euryhaline species, however, the extremes, not the fluctuation patterns, that determine their existence in a particular region. Attrill (2002) argues that absolute salinity tolerance seems to be the main factor behind species distribution in the Baltic Sea.

In summary, 3 Venice System boundaries were identifiable using our $\beta$-diversity approach. The first was at salinities around 30 and delimits the marine sector. The second was located at salinities around 18 and the third at salinities around 10. Since only stations with mean salinities above 5 were included in the present analysis, the presence of a boundary at a salinity of 5 could not be tested.

Below salinities of 30, the taxonomic groups echiurids, phoronids and sipunculids are not found. These taxa are composed of marine species that cannot survive in brackish water. Other groups, such as the anthozoans and the echinoderms, penetrate into the Baltic Sea and while they may survive at salinities of less than 15, they can no longer reproduce. Their occurrence correlates with inflow events of saline waters from the North Sea via the Great Belt.

Other groups have wider distributions along the salinity gradient. These include bivalves, gastropods, ne-
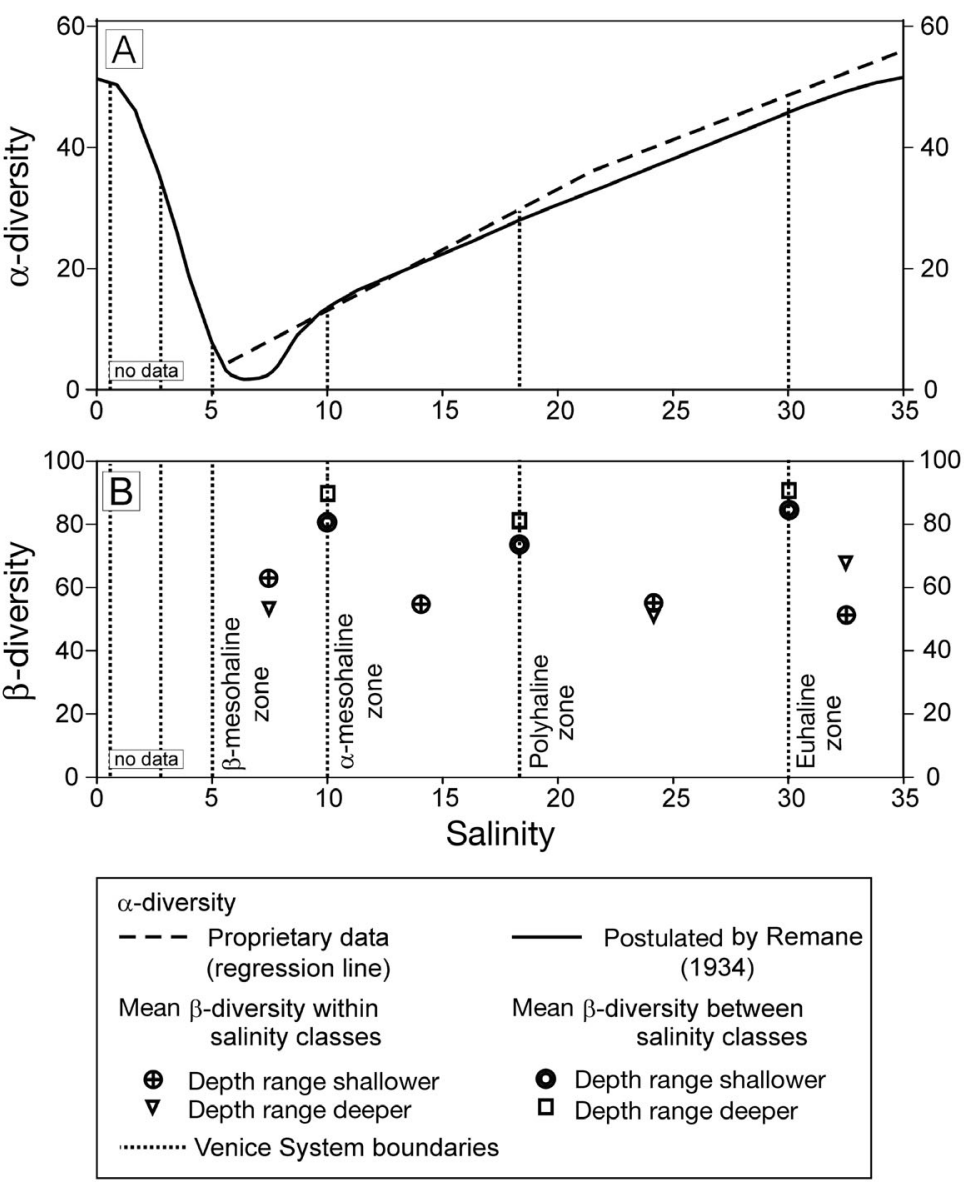

Fig. 9. (A) Model of $\alpha$-diversity (species richness) and (B) $\beta$-diversities $\left(\beta_{1-J}\right)$ vs. mean salinity. $\beta$-diversities within and between the salinity classes of the Venice System are shown

mertines, oligochaetes and polychaetes. Within these groups, however, individual species exhibit completely different salinity tolerances (Remane 1958). Polychaetes have the highest contribution to the species richness in the euhaline and polyhaline zone. The high species loss at lower salinities is mainly explained by the dominance of this group in the marine environment.

Here we have been able to substantiate that boundary areas exist along salinity gradients in the Baltic Sea, revealing a very high species turnover ( $\beta$-diversity) in this area with median complementarities of between 75 and $100 \%$. These boundary areas are consistent with the boundaries of the Venice System (Fig. 9). An extension of this study to the lowest salinity range from 0 to 5 is strongly recommended. However, there is strong evidence that species richness increases significantly below salinities of 3 , mainly due to the influence of freshwater insects and oligochaetes. This increase would most probably result in similarly high $\beta$-diversity values. 
Acknowledgements. We are very grateful to those colleagues and institutions that provided macrofaunal and sediment data. Much of the data used in this study came from the SMHI database SHARK (Svenskt HavsARKiv) and the BIOMAD database (Database on Marine Biological Monitoring Data, administered by the Department of Systems Ecology, Stockholm University) and were generated within the Swedish coordinated environmental monitoring programme. Additional data were provided by S. Wilhelms from the Bundesamt für Seeschifffahrt und Hydrografie, Hamburg, Germany, V. Didžiulis from the Coastal Research and Planning Institute, Klaipeda University, Lithuania, H. Sordyl from the Institut für Angewandte Ökologie, Neu Broderstorf, Germany, M. von Weber from the Landesamt für Umwelt, Naturschutz und Geologie (LUNG), Güstrow, Germany, and J. Warzocha from the National Marine Fisheries Research Institute, Gdynia, Poland. E. Łysiak-Pastuszak delivered Polish national HELCOM COMBINE monitoring data supplied by the Institute of Meteorology and Water Management Poland and owned by the Chief Inspectorate for Environmental Protection, Polish Ministry of Environment. Additional sediment data for some Swedish monitoring stations were provided by S. Agrenius from the Institutionen för Marin Ekologi, Kristinebergs Marina Forskningsstation, Sweden and by P. Göransson from the Miljökontoret Helsingborg, Sweden. Modeling work was performed on the supercomputers provided by the Norddeutscher Verbund für Hoch- und Höchstleistungsrechnen (HLRN) in Berlin and Hannover, Germany. We also acknowledge the work on the English text done by L. Cathrow and S. Forster.

\section{LITERATURE CITED}

Anderson MJ, Ellingsen KE, McArdle BH (2006) Multivariate dispersion as a measure of beta diversity. Ecol Lett 9:683-693

Attrill MJ (2002) A testable linear model for diversity trends in estuaries. J Anim Ecol 71:262-269

BACC author team (2008) Assessment of climate change in the Baltic Sea basin. Springer-Verlag, Berlin

> Berezina NA, Golubkov SM, Gubelit YI (2009) Structure of littoral zoocenoses in the macroalgae zones of the Neva River Estuary. Inland Water Biol 2:340-347

Bergström S, Carlsson B (1994) River runoff to the Baltic Sea: 1950-1990. Ambio 23:280-287

Bick A (2005) A new Spionidae (Polychaeta) from North Carolina, and a redescription of Marenzelleria wireni Augener, 1913, from Spitsbergen, with a key for all species of Marenzelleria. Helgol Mar Res 59:265-272

> Boyce RL, Ellison PC (2001) Choosing the best similarity index when performing fuzzy set ordination on binary data. J Veg Sci 12:711-720

Bulger AJ, Hayden BP, Monaco ME, Nelson DM, McCormickRay MG (1993) Biologically-based estuarine salinity zones derived from a multivariate analysis. Estuar Coast 16: 311-322

Caspers H (1959) Vorschläge einer Brackwassernomenklatur. Int Rev Gesamten Hydrobiol 44:313-315

Chainho P, Costa JL, Chaves ML, Lane MF, Dauer DM, Costa MJ (2006) Seasonal and spatial patterns of distribution of subtidal benthic invertebrate communities in the Mondego River, Portugal-a poikilohaline estuary. Hydrobiologia 555: 59-74

> Chainho P, Lane MF, Chaves ML, Costa JL, Costa MJ, Dauer DM (2007) Taxonomic suffciency as a useful tool for typology in a poikilohaline estuary. Hydrobiologia 587:63-78

Chao A, Chazdon RL, Colwell RK, Shen TJ (2005) A new statistical approach for assessing similarity of species composition with incidence and abundance data. Ecol Lett 8:148-159

Chytrý M, Sedláková I, Tichý L (2001) Species richness and spe- cies turnover in a successional heathland. Appl Veg Sci 4: 89-96

Clarke KR (1993) Non-parametric multivariate analyses of changes in community structure. Aust J Ecol 18:117-143

Clarke KR, Gorley RN (2006) PRIMER v6: user manual/tutorial. PRIMER-E, Plymouth

Clarke KR, Somerfield PJ, Chapman MG (2006) On resemblance measures for ecological studies, including taxonomic dissimilarities and a zero-adjusted Bray-Curtis coefficient for denuded assemblages. J Exp Mar Biol Ecol 330:55-80

Colwell RK (2005) EstimateS: statistical estimation of species richness and shared species from samples (version 7.50). Available at: purl.oclc.org/estimates

Colwell RK, Coddington JA (1994) Estimating terrestrial biodiversity through extrapolation. Philos Trans R Soc Lond B 345:101-118

Condit R, Pitman N, Leigh EG, Chave J and others (2002) Betadiversity in tropical forest trees. Science 295:666-669

> Dauer DM, Ewing RM, Rodi AJ (1987) Macrobenthic distribution within the sediment along an estuarine salinity gradient. Int Rev Gesamten Hydrobiol 72:529-538

$>$ Deaton LE, Greenberg MJ (1986) There is no horohalinicum. Estuaries 9:20-30

> den Hartog C (1964) Typologie des Brackwassers. Helgol Wiss Meeresunters 10:377-390

Denœud L, Guénoche A (2006) Comparison of distance indices between partitions. In: Batagelj V, Bock $\mathrm{HH}$, Ferligoj A, Žiberna A (eds) Data science and classification, studies in classification, data analysis, and knowledge organization. Springer, Berlin, p 21-28

Eleftheriou A, Moore DC (2005) Macrofauna techniques. In: Eleftheriou A, McIntyre AD (eds) Methods for the study of marine benthos, 3rd edn. Blackwell, Oxford, p 160-228

- Ellingsen KE (2002) Soft-sediment benthic biodiversity on the continental shelf in relation to environmental variability. Mar Ecol Prog Ser 232:15-27

Ellingsen KE, Gray JS (2002) Spatial patterns of benthic diversity: is there a latitudinal gradient along the Norwegian continental shelf? J Anim Ecol 71:373-389

Ersts PJ (2009) Geographic Distance Matrix Generator, version 1.2.3. American Museum of Natural History, Center for Biodiversity and Conservation. Available at: biodiversityinformatics.amnh.org/open_source/gdmg. Accessed on 12 Oct 2009

European Union (2000) Directive 2000/60/EC of the European Parliament and of the Council of 23 October 2000 establishing a framework for community action in the field of water policy. Official Journal L 327/1. European Commission, Brussels

Ferreira FC, Petrere M (2009) The fish zonation of the Itanhaém river basin in the Atlantic Forest of southeast Brasil. Hydrobiologia 636:11-24

Feser F, Weisse R, von Storch H (2001) Multi-decadal atmospheric modeling for Europe yields multi-purpose data. EOS Trans Am Geophys Union 82:305-310

Gaston GR, Rakocinski CF, Brown SS, Cleveland CM (1998) Trophic function in estuaries: response of macrobenthos to natural and contaminant gradients. Mar Freshwat Res 49: 833-846

Giberto DA, Bremec CS, Cortelezzi A, Rodrigues Capitulo A, Brazeiro A (2007) Ecological boundaries in estuaries: macrobenthic $\beta$-diversity in the Río de la Plata system $\left(34-36^{\circ} \mathrm{S}\right)$. J Mar Biol Assoc UK 87:377-381

> Gleason HA (1926) The individualistic concept of the plant association. Bull Torrey Bot Club 53:7-26

Gray JS (2000) The measurement of marine species diversity, with an application to the benthic fauna of the Norwegian continental shelf. J Exp Mar Biol Ecol 250:23-49 
Greenwood MFD (2007) Nekton community change along estuarine salinity gradients: can salinity zones be defined? Estuar Coast 30:537-542

HELCOM (1986) Water balance of the Baltic Sea: a regional cooperation project of the Baltic Sea states, International Summary Report. Balt Sea Environ Proc No. 16, 1-174

HELCOM (1988) Guidelines for the Baltic Sea monitoring programme for the third stage. Part D: Biological determinants. Balt Sea Environ Proc No. 27, p 1-161

HELCOM (2003) The 2002 oxygen depletion event in the Kattegat, Belt Sea and western Baltic. Balt Sea Environ Proc No. 90, p 1-64

Hillebrand H, Soininen J, Snoeijs P (2010) Warming leads to higher species turnover in a coastal ecosystem. Glob Change Biol 16:1181-1193

Hiltermann H (1963) Klassifikation rezenter Brack- und SalinarWässer in ihrer Anwendung für fossile Bildungen. Z Dtsch Ges Geowiss 115:463-496

Izsak C, Price ARG (2001) Measuring $\beta$-diversity using a taxonomic similarity index, and its relation to spatial scale. Mar Ecol Prog Ser 215:69-77

> Josefson AB (2009) Additive partitioning of estuarine benthic macroinvertebrate diversity across multiple spatial scales. Mar Ecol Prog Ser 396:283-292

Josefson AB, Hansen JLS (2004) Species richness of benthic macrofauna in Danish estuaries and coastal areas. Glob Ecol Biogeogr 13:273-288

Koleff P, Gaston KJ, Lennon JJ (2003) Measuring beta diversity for presence-absence data. J Anim Ecol 72:367-382

Kotta J, Lauringson V, Kotta I (2007) Response of zoobenthic communities to changing eutrophication in the northern Baltic Sea. Hydrobiologia 580:97-108

> Legendre P, Borcard D, Peres-Neto PR (2005) Analyzing beta diversity: partitioning the spatial variation of community composition data. Ecol Monogr 75:435-450

Leppäkoski E, Olenin S (2000) Non-native species and rates of spread: lessons from the brackish Baltic Sea. Biol Invasions 2:151-163

Leppäkoski E, Gollasch S, Gruszka P, Ojaveer H, Olenin S, Panov V (2002) The Baltic - a sea of invaders. Can J Fish Aquat Sci 59:1175-1188

Magurran AE (2004) Measuring biological diversity. Blackwell, Malden, MA

Meriläinen JJ (1984) Zonation of the macrozoobenthos in the Kyrönjoki estuary in the Bothnian Bay, Finland. Ann Zool Fenn 21:89-104

Mumby PJ (2001) Beta and habitat diversity in marine systems: a new approach to measurement, scaling and interpretation. Oecologia 128:274-280

> Nanami A, Saito H, Akita T, Motomatsu K, Kuwahara H (2005) Spatial distribution and assemblage structure of macrobenthic invertebrates in a brackish lake in relation to environmental variables. Estuar Coast Shelf Sci 63:167-176

> Neumann T, Schernewski G (2008) Eutrophication in the Baltic Sea and shifts in nitrogen fixation analyzed with a 3D ecosystem model. J Mar Syst 74:592-602 [doi: 10.1016/ j.jmarsys.2008.05.003]

Novotny V, Weiblen GD (2005) From communities to continents: beta diversity of herbivorous insects. Ann Zool Fenn 42: 463-475

Pacanowski RC, Griffies SM (2000) MOM 3.0 Manual. NOAA/ Geophysical Fluid Dynamics Laboratory, Princeton, NJ

> Perus J, Bonsdorff E (2004) Long-term changes in macrozoobenthos in the Åland archipelago, northern Baltic Sea. J Sea Res 52:45-56

Piscart C, Moreteau JC, Beisel JN (2005) Biodiversity and structure of macroinvertebrate communities along a small permanent salinity gradient (Meurthe River, France). Hydrobi- ologia 551:227-236

Powilleit M, Kube J, Maslowski J, Warzocha J (1995) Distribution of macrobenthic invertebrates in the Pomeranian Bay (southern Baltic) in 1993/94. Bull Sea Fish Inst Gdynia 136: 75-87

Remane A (1934) Die Brackwasserfauna. Verh Deut Zool Ges $36: 34-74$

Remane A (1958) Ökologie des Brackwassers. In: Remane A, Schlieper C (eds) Die Biologie des Brackwassers. Die Binnengewässer 22. E. Schweizerbart'sche Verlagsbuchhandlung, Stuttgart

Rumohr H, Karakassis I, Nørrevang Jensen J (2001) Estimating species richness, abundance and diversity with 70 macrobenthic replicates in the Western Baltic. Mar Ecol Prog Ser 214:103-110

Shannon CE, Weaver W (1949) The mathematical theory of communication. University of Illinois Press, Chicago, IL

Shin PKS, Ellingsen KE (2004) Spatial patterns of soft-sediment benthic diversity in subtropical Hong Kong waters. Mar Ecol Prog Ser 276:25-35

> Sousa R, Dias S, Freitas V, Antunes C (2008) Subtidal macrozoobenthic assemblages along the River Minho estuarine gradient (north-west Iberian Peninsula). Aquat Conserv: Mar Freshw Ecosyst 18:1063-1077

Stålnacke P, Grimvall A, Sundblad K, Tonderski A (1999) Estimation of riverine loads of nitrogen and phosphorus to the Baltic Sea, 1970-1993. Environ Monit Assess 58:173-200

Stohlgren TJ, Chong GW, Kalkhan MA, Schell LD (1997) Multiscale sampling of plant diversity: effects of minimum mapping unit size. Ecol Appl 7:1064-1074

Telesh IV, Schubert H, Skarlato SO (2011) Revisiting Remane's concept: evidence for high plankton diversity and a protistan species maximum in the horohalinicum of the Baltic Sea. Mar Ecol Prog Ser 421:1-11

- Terlizzi A, Anderson MJ, Bevilacqua S, Fraschetti S, WłodarskaKowalczuk M, Ellingsen KE (2009) Beta diversity and taxonomic sufficiency: do higher-level taxa reflect heterogeneity in species composition? Divers Distrib 15:450-458

Teske PR, Wooldridge T (2004) Affinities of some common estuarine macroinvertebrates to salinity and sediment type: empirical data from Eastern Cape estuaries, South Africa. Afr Zool 39:183-192

Tuomisto H (2010) A diversity of beta diversities: straightening up a concept gone awry. Part 2. Quantifying beta diversity and related phenomena. Ecography 33:23-45

Tuomisto H, Ruokolainen K (2008) Analyzing or explaining beta diversity? Reply. Ecology 89:3244-3256

Udalov AA, Burkovskii IV, Stolyarov AP, Chertoprud MV and others (2004) Changes in the general characteristics of micro-, meio-, and macrobenthos along the salinity gradient in the White Sea estuary. Oceanology 44:514-525

Vellend M (2001) Do commonly used indices of $\beta$-diversity measure species turnover? J Veg Sci 12:545-552

von Weber M (2004) Die EU-Wasserrahmenrichtlinie-Ziele, Instrumente und Umsetzung in den Küstengewässern. Rostock Meeresbiol Beitr 13:233-240

Wallentinus I (1991) The Baltic Sea gradient. In: Mathieson AC, Nienhuis PH (eds) Intertidal and littoral ecosystems. Ecosystems of the world, Vol 24. Elsevier, Amsterdam, p 83-108

- Whittaker RH (1960) Vegetation of the Siskiyou mountains, Oregon and California. Ecol Monogr 30:279-338

> Whittaker RH (1972) Evolution and measurement of species diversity. Taxon 21:213-251

Wilson MV, Shmida A (1984) Measuring beta diversity with presence-absence data. J Ecol 72:1055-1064

Zettler ML, Schiedek D, Bobertz B (2007) Benthic biodiversity indices versus salinity gradient in the southern Baltic Sea. Mar Pollut Bull 55:258-270 